\title{
Review \\ Roles of Cannabidiol in Reversing Proteinopathies
}

\author{
Raju Dash ${ }^{1}$, Md. Chayan Ali ${ }^{2 \dagger}$, Israt Jahan ${ }^{3 \dagger}$, Yeasmin Akter Munni ${ }^{1+}$, Sarmistha Mitra ${ }^{4}$, Md. Abdul \\ Hannan ${ }^{1,5}$, Binod Timalsina ${ }^{1}$, Diyah Fatimah Oktaviani ${ }^{1}$, Ho Jin Choi ${ }^{1}$, Il Soo Moon ${ }^{1 *}$ \\ ${ }^{1}$ Department of Anatomy, Dongguk University College of Medicine, Gyeongju 38066, Republic of Korea \\ ${ }^{2}$ Department of Biotechnology and Genetic Engineering, Faculty of Biological Sciences, Islamic University, Kushtia \\ 7003, Bangladesh \\ ${ }^{3}$ Department of Pharmacy, Faculty of Life and Earth Sciences, Jagannath University, Dhaka 1100, Bangladesh. \\ 4Plasma Bioscience Research Center and Department of Plasma Bio display, Kwangwoon University, Seoul 01897, \\ Republic of Korea \\ ${ }^{5}$ Department of Biochemistry and Molecular Biology, Bangladesh Agricultural University, Mymensingh 2202, \\ Bangladesh \\ 'These authors have contributed equally. \\ ${ }^{*}$ Corresponding author: Il Soo Moon \\ Mailing address: Department of Anatomy, Dongguk University College of Medicine, 123 Dongdae-ro, Gyeongju \\ 38066, Republic of Korea \\ Phone: +82-54-770-2414 \\ Fax: +82-54-770-2447 \\ Email: moonis@dongguk.ac.kr
}

\begin{abstract}
Cannabidiol is a well-known non-psychotropic phytocannabinoid from Cannabis sativa, which exerts a broad range of neuropharmacological activities in the central nervous systems. Over the past years, compelling evidence from preclinical and clinical studies support therapeutic potentials of cannabidiol in various neurological disorders, including neurodegenerative diseases. Neurodegenerative diseases are characterized by the accumulation of misfolded or aggregated protein due to the defective protein homeostasis or proteostasis network, termed as proteinopathies. Because of its role in the protein homeostasis network, cannabidiol could be a potent molecule to revert not only age-associated neurodegeneration but also other protein misfolding disorders. In this review, we discuss the potentiality of cannabidiol as a pharmacological modulator of the proteostasis network, highlighting its neuroprotective and aggregates clearing system inducing potentials in the neurodegenerative diseases.
\end{abstract}

Keywords: Cannabidiol; Alzheimer's disease; Huntington's disease; Multiple sclerosis; Parkinson's disease; Prion disease; Proteinopathies

\section{Introduction}

Disruption in protein homeostasis (proteostasis) and protein misfolding are two major drivers in the pathobiology of neurodegenerative diseases (NDDs) including Alzheimer's disease (AD), Parkinson's disease (PD), Huntington's disease (HD), Amyotrophic lateral sclerosis (ALS) and multiple sclerosis (MS). NDDs are generally characterized by the presence of protein aggregates either in the nucleus or cytoplasm $[1,2]$, and the region-specific neuronal death with a consequence of motor and cognitive deficits [3,4]. A line of evidence supports the concept that NDDs are proteinopathies, where they share fundamental features of protein aggregate, for example, tau, and amyloid- $\beta$ in $\mathrm{AD}, \alpha$-synuclein in PD, huntingtin (Htt) 
in HD, etc. [5-7]. Evidence from the recent studies correlates the higher incidence of NDD with the progressive failure of the proteostasis network, which results in proteotoxic stress that reduces both repair and/or clearance of misfolded protein; and thus contributes to pathological aging [8-11]. The proteostasis network is impaired by oxidative stress, which is a pathological condition arising from excess production of reactive oxygen species (ROS) due to starvation, exposure to antibiotics [12], inflammation [13], diseaseassociated mutations, polymorphisms, energetic deficits and aging [14-17]. Oxidative stress plays vulnerable roles in disrupting proteostasis by causing oxidative damage and neuroinflammation, leading to cell death $[17,18]$.

Accumulating evidence suggests that endocannabinoid systems regulate the functionality of redox homeostasis in different cell types [19,20], thus maintain an equilibrium state between the redox system and pro-oxidant state [21,22]. The endocannabinoid systems, consisting of cannabinoid receptors (CB1 and CB2), are either activated or antagonized by endocannabinoids and phytocannabinoids [23]. Phytocannabinoids, such as cannabidiol (CBD), cannabivarin, delta-9-tetrahydrocannabinol (THC), cannabidivarin, and cannabigerol, have been widely studied for their involvement in endocannabinoid systems [24]. CBD is available in Cannabis sativa, categorized as a phytocannabinoid of cannabaece family [25-27], and is one of the fascinating non-psychoactive agents with well-known anti-oxidant and antiinflammatory properties [28,29].

CBD has shown to provide neuroprotection [30] and thus become a therapeutic option in neurodegenerative disorders like AD, PD, HD, ALS, and MS, where treatment slows down disease progression [31]. Remarkedly, disease-modifying mechanisms of CBD are attributed to its antioxidant, antiinflammatory, and neuroprotective potentials; the precise mechanisms, however, remain unclear, specifically in the regulation of proteostasis system [32]. In this review, an effort has been made to connect CBD mediated pharmacological effects with proteostasis system, providing a more extensive area for future research on CBD pharmacology, in the management of neurodegenerative disorders.

\section{Cannabidiol chemistry, bioavailability, and toxicity}

The plant, C. sativa, serves as a primary source of CBD, where CBD is available up to $40 \%$ in the organic extraction [33]. CBD from cannabis was first reported in the late 1930s, and purified in 1940; however, structure and stereochemistry were first elucidated in 1960s by Mechoulam et al. [34]. The biosynthesis of CBD is usually triggered by the leading precursor cannabigerolic acid, which is derived from the two phytocannabinoid precursors, divarinic acid and olivetolic acid. Cannabigerolic acid is further converted into cannabichromenic acid, tetrahydrocannabinolic acid, and cannabidiolic acid, where cannabidiolic acid forms CBD [35,36]. Comparatively, CBD is the major non-psychotomimetic compound present in the plant, well-tolerated [37], and has a broad spectrum of potential therapeutic properties, including anxiolytic [38], anticonvulsant [24], anti-inflammatory [39-41], neuroprotective [38,42-45], and immunomodulatory [46]. In combination therapy, CBD alleviates some of the adverse effects of THC, such as cognitive impairment, psychosis, schizophrenia-like effects [47-49].

The pharmacokinetics of CBD is quite complex, and various studies suggest several potential routes of administration. The oral bioavailability of CBD is ranged from $13 \%$ to $19 \%$ with a substantial first-pass impact, whereas the systemic bioavailability of inhaled CBD was $31 \%$ (range $11-45 \%$ ) for a community of cannabis users. The specification of plasma was identical to $\triangle 9$-THC. At chronically administered oral daily doses of CBD $10 \mathrm{mg} / \mathrm{kg} / \mathrm{day}$, the average plasma concentration of CBD was $5.9-11.2 \mathrm{mg} / \mathrm{mL}$ [50]. When injected, CBD is absorbed 
rapidly and easily crosses the blood-brain barrier (BBB), owing to its lipophilicity, which in turn provides sustained release of CBD [51]. CBD delivery is controlled by its high lipophilicity, and an approximate volume of distribution $\sim 32 \mathrm{~L} / \mathrm{kg}$ with prompt dissemination in the fat tissue, brain, and different other organs [52]. CBD is also exceedingly protein-bound, and $\sim 10 \%$ is associated with the circulation of red blood cells [53]. It is predominantly metabolized by the liver, as in other cannabinoids, whereby cytochrome P450 (CYP) enzymes, primarily by CYP3A and CYP2C isozymes groups hydroxylating it to 7-OHCBD. This metabolite is then substantially more metabolized in the liver, and the subsequent metabolites are eliminated to feces and slightly less into the urine. The half-life of CBD is 18 to 32 hours in humans, with a clearance of $960-1560 \mathrm{ml} / \mathrm{min}$ after the single dosage given in prolonged cannabis users [54]. Without worsening of psychotic symptoms, CBD has well endured in patients with dosages up to $600 \mathrm{mg}$ [55]. No significant CNS impacts or consequences for vital signs or mood changes were identified in a minority of placebo-controlled studies conducted at dosages up to 1,500 mg/day (p.o.) or $30 \mathrm{mg}$ (i.v.) in both intense and persistent administration [56]. For adults, there is a possible hazard of immunosuppression, because CBD has been identified to repress anti-inflammatory factors IL10 and IL8 as well as to induce apoptosis of lymphocytes [55,57]. In humans and other species, cannabidiol exhibits very low toxicity: with an LD50 of $212 \mathrm{mg} / \mathrm{kg}$ after administered intravenously to rhesus monkeys [58]. The oral $\mathrm{LD}_{50}$ has not been reported yet; however, Rosenkrantz has demonstrated, an oral dose of CBD that was 20-50 times higher than intravenous dose was sufficiently high to cause severe toxicity [58]. Besides, a broad range of studies has failed to identify CBD-inducing mutagenic or teratogenic effects [50].

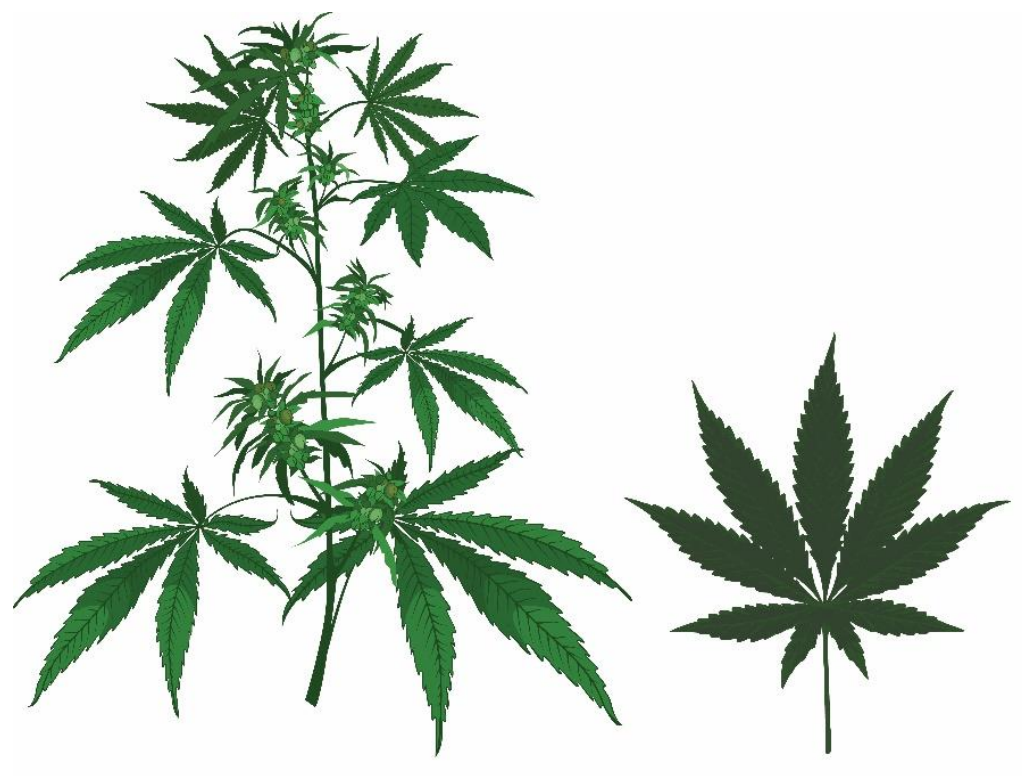

Cannabis sativa

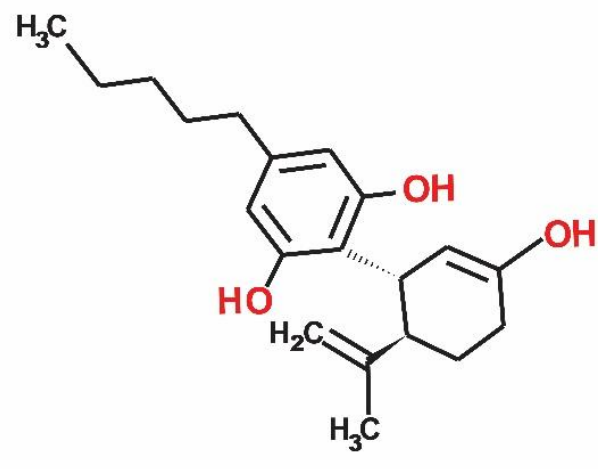

Cannabidiol (CBD)

Figure 1. The major source (Cannabis sativa) and chemical structure of cannabidiol.

\section{Molecular hallmarks of neurodegeneration}


Disposition of misfolded proteins or protein aggregates in the brain is the main hallmarks of neurodegeneration, where the NDDs are categorized based on the type of protein deposition or by known genetic mechanisms. These disorders, caused by misfolded proteins, are also known as proteinopathies, where the protein conformation is being critically altered [59,60]. For each disease, the clinical manifestation is initiated with the repeated production of a specific protein, which is misfolded, aggregated, and, hence, affects specific neurons [61]. In the basal state, misfolded proteins are either refolded correctly or degraded by the quality control system, like by chaperone proteins [62]. During cellular aging, under proteotoxic stress, or due to mutation, misfolded proteins escape this system, and then aggregated into amorphous assemblies and oligomers, ranging to highly ordered amyloid fibrils and plaques. Once formed, higher-order amyloid aggregates are highly resistant to degradation. Several factors play a critical role in favor of this transition, including post-translational modifications, environmental changes, chemical alterations, in addition to genetic mutations. These factors alter the hydrophobicity or net charge of the protein, which reduces conformational stability and also affect the protein quality control system [63].

Furthermore, cellular insults, like calcium-induced protein misfolding, mitochondrial dysfunction, and inflammation, are also associated with protein aggregation, where mitochondrial dysfunction confers upregulation of ROS/RNS (reactive nitrogen species) in the cells, which leads to cell death [64]. On the other hand, overstimulation of NMDA receptors also caused excessive intracellular calcium accumulation, which promotes ROS/RNS production that impedes quality control mechanisms. Misfolded proteins also activate microglia and astrocytes, causing the release of pro-inflammatory mediators and cytokines that activate several mechanisms, which follows the ROS/RNS generations, mitochondrial dysfunction and neuronal apoptosis [65]. Moreover, excessive aggregation leads to develop a vicious cycle of cell toxicity, where they interact with the membrane systems and establish transmembrane pores, further leading to an influx of calcium [66]. In this regard, CBD could be a fascinating molecule for the particular interest in neurodegenerative disorders, because of having anti-inflammatory, antioxidant, and neuroprotective potentiality. A wealth of literature highlights the therapeutic roles of CBD in models of neurotoxicity and neurodegenerative disorders, which will be discussed in subsequent sections.

\section{CBD regulation in oxidative stress}

Oxidative stress (OS) is a pathological condition resulting from an imbalance of proand anti-oxidant molecules. [67]. Because of high metabolic demand and huge turnover in brain cells, neurons are particularly highly prone to OS. Prolonged OS causes a depletion of cellular antioxidants enzymes such as superoxide dismutase (SOD), catalases (CAT), glutathione peroxidase (GPx), and non-enzymatic components like glutathione (GSH)), leaving the cellular antioxidant defense system exhausted [68,69]. OS may also lead to inflammation, protein misfolding, mitochondrial dysfunction, impairment of the DNA repair system, glial activation, and ultimately cellular damages, which are critically implicated in the development of neurodegenerative disorders [70,71].

Several studies demonstrate the neuroprotective effects of CBD, owing to its antioxidant activity. A study by Pan et al. showed that CBD mitigated cisplatin-induced oxidative/nitrosative stress by downregulating the expression of superoxide-generating enzymes RENOX (NOX4) and NOX1 in mice models [72]. In the Fenton reaction, CBD can transfer electrons under variable voltage potential as well as prevent dihydrorhodamine oxidation similar to the synthetic antioxidant butyled hydroxy toluene (BHT). CBD also protects neurons incubated with tert- 
butyl hydroperoxide in a concentration-dependent manner [73]. Moreover, in the glutamate neurotoxicity model, CBD was shown higher neuroprotective efficacy than the popular antioxidants, $\alpha$-tocopherol (vitamin E), and ascorbate (vitamin C) [73]. Iuvone et al. demonstrated that CBD $(10 \mu \mathrm{M})$ attenuated apoptosis in PC12 cells by reducing intracellular calcium accumulation, lipid peroxidation, ROS generation, and downregulating caspase-3 level. CBD also demonstrated an antioxidant effect by inhibiting inducible nitric oxide synthase protein expression and nitric oxide production, followed by blocking p38 MAP kinase phosphorylation and the NF- $\kappa \mathrm{B}$ activation [74,75]. In the $\mathrm{H}_{2} \mathrm{O}_{2}$ induced OS model, CBD has shown to protect primary hippocampal neurons, oligodendrocyte progenitor cells, and cerebellar granule cells [7678]. Juknat and his colleagues have paid an effort to identify underlying molecular mechanisms of CBD mediated antioxidation in BV-2 microglial cells [79]. The study reveals that $\mathrm{CBD}$ can modulate redox homeostasis and ROS generation by regulating $\mathrm{Nrf2/HO}-1$ axis and (EpRE/ARE)-Nrf2/ATF4 system, respectively. Similar results were observed in a study with keratinocyte [80]. However, a recent study identified CBD, as a relatively week inducer of Nrf2, although it strongly upregulates HMOX1 by inhibiting BACH1 [81]. Nrf2 is a transcription regulator of various antioxidant factors, whereas HMOX1, one of the targets of Nrf2, is an enzyme that provides antioxidant properties by the rate-limiting reaction in heme catabolism [82].

\section{CBD mediated neuroprotection against neuroinflammation}

The phenomenon of neuroinflammation includes a complex reaction of glial activation, related to inflammatory mediators like chemokines or cytokines secretion, and reactive oxygen and nitrogen species generations [83]. Accumulation of misfolded protein or protein aggregates is often triggered by ROS/RNS [76,84], which in turn activates pro-inflammatory responses and thus sustains neuroinflammation [85]. Notably, molecular pathways regulated by $\mathrm{CBD}$, as described in OS, are also implicated in neuroinflammation. As a result, CBD can manage neuroinflammation by not only reducing OS but also by producing anti-inflammatory substances and also regulates pro-inflammatory responses [40,86-89].

Several findings demonstrated that pro-inflammatory responses, including chemokines and cytokines, are mediated through NF- $\kappa \mathrm{B}$ signaling, which promotes inflammatory cascade upon the microglial activation [30,90]. NF- $\kappa$ B signaling consequently plays an essential role in neuronal plasticity as well as in the cellular response to brain injury by upregulating cytokines in astrocytes and microglia, especially TNF- $\alpha$, and IL-6 and many others reviewed elsewhere [91]. The regulation of NF- $\kappa B$ signaling, however, is repressed by the activation of peroxisome proliferator-activated receptor $\gamma$ (PPAR- $\gamma$ ) [92]. A line of studies demonstrated that CBD reduced the amount of IL-1 $\beta$, IFN- $\beta$, TNF- $\alpha$, IFN- $\gamma$, IL-6, IL-17, NO, and COX-2 through the activation of PPAR- $\gamma$ [93-98]; while increasing the production of anti-inflammatory cytokines IL-4 and IL-10, and impeding iNOS expression [94]. In the lipopolysaccharide-stimulated animal model, CBD reduced the secretion of pro-inflammatory cytokines (IL-1 $\beta$ and TNF- $\alpha$ ), and also other noncytokine compounds. By inhibiting ROS/NF- $\kappa B$ pathway, CBD can lower glucose uptake in the microglial cell, which is essential for the activation of microglia [86,99], followed by downregulating NADPH oxidase and $\mathrm{I} \kappa \mathrm{B}$ kinase-2 [86].

Additionally, CBD showed a suppressive role in the immune system, as evidenced by improving innate and adaptive immune responses in a chronic inflammatory model [100]. Ruiz-Valdepeñas et al. represented that CBD reduced leucocyte recruitment and TNF expression in the central nervous system [101]. Furthermore, Juknat et al. found that CBD regulates Th17 proliferation and STAT1 /STAT3 balance, which suppresses microglial cell activation [79] and also reduces inflammatory cytokine IL-6 and IL-17 secretion [102]. Immune regulatory effects of CBD are based on the strong upregulation of CD4 ${ }^{+}$and CD25T cells by inhibitor molecules LAG3 and CD69 [102]. Besides, activation of mitogen-activated protein kinases like p38/MAP-kinases may lead to the upregulation of pro-inflammatory mediators during 
inflammation. Interestingly, CBD can inhibit the p38 phosphorylation, which sequentially reduces the neurotoxic effects with uncontrolled immune reactions [103].

The positive effects of CBD are linked to the expression of brain-derived neurotrophic factor (BDNF) and pro-inflammatory cytokines to interact with intracellular pathways in neuronal survival $[33,38]$. BDNF is a vital neurotrophin for neuronal development and survival, cognitive function, and also for synaptic plasticity [104]. Barichello et al. found that low brain BDNF levels and augmented proinflammatory cytokines in rats exposed to an experimental model of meningitis were associated with poor cognitive performance. In this regard, CBD therapy minimized these effects [105]. Using rat hippocampus, a study based on amphetamine-induced OS model showed that CBD increased the levels of BDNF as a model to investigate mania [106]. On the other hand, the upregulation of BDNF expression by CBD was also found to be correlated with anti-inflammatory activity, decreasing TNF- $\alpha$ and IL-6 levels in the prefrontal cortex and the hippocampus [42].

In combination therapy, supplementation of CBD with THC suppresses mi-RNA mediated neuroinflammation [107,108]. This conjugated therapy reduces Th1 and Th2 expression and neuroinflammation in murine experimental autoimmune encephalomyelitis (EAE) model system, which was mediated through CB1 and CB2 receptors. Again, CBD therapy combination with THC has been reported to reduce CD4+ T cell proliferation in the brain and pro-inflammatory cytokines IL-1 $\beta$, IL-6, INF$\gamma$, IL-17, TNF- $\alpha$, and TBX21 and enhanced the production of anti-inflammatory molecules like as STAT5b, FoxP3, TGF- $\beta$, IL-4, and IL-10. The miRNA microarray data revealed that THC+CBD upregulated miR-706$5 p$ and miR-7116 whereas, suppressed miR-21a-5p, miR-31-5p, miR-122-5p, miR-146a-5p, miR-150-5p, miR155-5p, and miR-27b-5p [109]. The pathway analysis revealed that most of the downregulated miRNA's targeted cell cycle-arrest and apoptosis molecules, such as CCNG1, CDKN2A, and BCL2L11 and antiinflammatory molecules such as FoxP3 and SOCS1 [109].

Studies suggested that CBD has no or little effect on endocannabinoid receptors. However, depending on the concentration, CBD can act as both agonist or antagonist to the various receptors, including ionotropic (TRP) as well as voltage-gated sodium channel, nuclear (PPAR) receptors, and also cannabinoid receptors (CB1 and CB2), albeit [110-112]. In this way, CBD regulates redox balance, and collectively provides an anti-inflammatory effect by reducing OS [113]. For a detailed understanding, readers are referred to a comprehensive review [114]. Besides, based on our discussion, we provide an illustration, highlighting CBD mechanism of action in OS and inflammation mediated through PPAR- $\gamma$ receptor (Figure 2). 


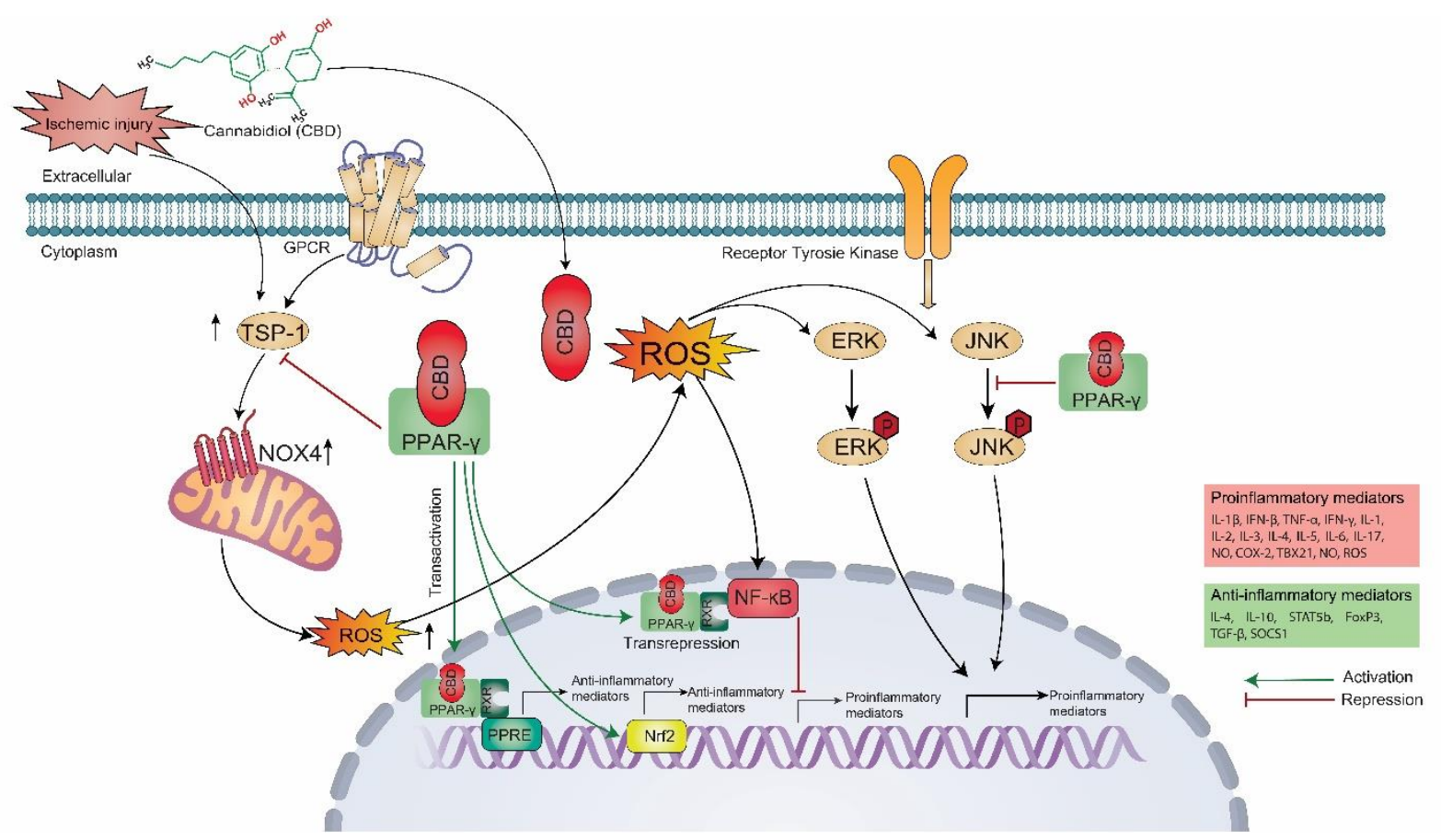

Figure 2. Potential mechanisms of CBD as a PPAR- $\gamma$ agonist to attenuate oxidative stress and inflammation. During oxygen deprivation, ROS generated through the upregulation of NOX4 in a TSP-1 dependent manner [115]. In that case, CBD binds and activates PPAR- $\gamma$, which in turn inhibits TSP-1 expression and signaling. PPAR- $\gamma$ activation by CBD also enhances antioxidant gene transcription by regulating transcription factor PPRE. Furthermore, PPAR- $\gamma$ activation transrepress NF- $\kappa \mathrm{B}$, and reduce proinflammatory cytokine secretion. CBDPPAR- $\gamma$ also inhibits JNK phosphorylation, resulting in decreased inflammatory response and oxidative stress. In addition, PPAR- $\gamma$ activation also induces transcription factor, NRF2, which reduces the inflammatory damage by enhancing expression of anti-inflammatory molecules. Here, green arrow represents activation of signaling and close red arrow represents inhibition of signaling. CBD, Cannabidiol; ROS, Reactive oxygen species; NOX4, Nicotinamide adenine dinucleotide phosphate oxidase 4; TSP-1, Thrombospondin-1; PPAR- $\gamma$, Peroxisome proliferator-activated receptor $\gamma$; PPRE, Peroxisome-proliferatorresponsive element; NF-kB, Nuclear factor-kappa B; JNK, Jun N-terminal kinases; NRF2, Nuclear factor erythroid 2-related factor 2.

\section{CBD Protects calcium-induced protein misfolding}

Calcium $\left(\mathrm{Ca}^{2+}\right)$ ions are the critical factor in intracellular signaling by regulating second messengers in the systems and used as a cofactor for some enzymes as well as bone formation. Although $\mathrm{Ca}^{2+}$ is prominent in cell physiology, its imbalance severely disrupts protein conformation [116]. Growing evidence supports the concept that the accumulation of excessive $\mathrm{Ca}^{2+}$ in the cell induces OS, which promotes protein aggregation, leading to cell death. Oxidative reactive species, such as ROS/RNS modify misfolded proteins to be highly oxidized and cross-linked, leaving them more prone to aggregates. These aggregated forms act as endogenous proteasomal inhibitors [70]. Consequently, reduced activity of the proteasomal system, the primary machinery for the removal of oxidized and misfolded protein leads to further accumulation of protein aggregate [117-121]. These protein aggregates can interact with the lipid bilayer of the cell membranes, causing membrane disruption or pore formation [122,123], which eventually disrupts ion homeostasis $[124,125]$. Furthermore, studies also showed an interaction between protein aggregates 
with cellular receptors, including mGluR5s, causing gain or loss of function in the signaling platform, resulting in the upregulation of NMDAR (N-methyl-D-aspartic acid receptor) dependent $\mathrm{Ca}^{2+}$ response [124]. NMDAR is one of the ionotropic glutamate receptors dealing with the $\mathrm{Ca}^{2+}$ regulation, along with $\mathrm{Na}^{+}$and $\mathrm{K}^{+}$in the cytoplasm [126,127]. However, overstimulation of NMDAR exaggerates the massive influx of $\mathrm{Ca}^{2+}$, which leads to energy loss with depolarization of mitochondrial $\mathrm{Ca}^{2+}$, and neuronal apoptosis by the activation of caspase pathways [128]. An excessive influx of $\mathrm{Ca}^{2+}$ gives rise to the production of ROS successively with the rising oxygen tension [129].

Several studies showed that CBD has anticonvulsant activity [130-132], focusing its effect on NMDAR regulation (Figure 3). Indeed, Azza B.El-Remessy et al. found that CBD decreased nitrite/nitrate, lipid peroxides, and nitrotyrosine expression, which subsequently protects neurons from NMDA induced injury [133]. Moreover, CBD was shown to inhibit glutamate release in the brain hypoxia model by acting on both CB2 and adenosine receptors but mainly on $A_{2 A}$ receptor [134]. Linge et al. found a correlation between CBD mediated glutamate signaling and serotonergic systems, where glutamate regulation is maintained by 5-HT1A receptor-dependent mechanism [24]. Strikingly, Gobira et al. found that activation of mTOR by CBD is associated with a subsequent reduction in glutamate release [135]. However, substantial evidence indicates that CBD behaves as an antagonist for chaperone protein $\sigma 1 \mathrm{R}$, which is a viable target to treat neuropathic pain by reducing the influence of glutamate NMDARs [136-139]. The o1R antagonist also inhibits $G$ protein-coupled receptors (GPCRs), which subsequently reduce the actions of NMDARs [140,141]. They produce secondary messengers, control homeostasis of calcium by triggering PKA, which is responsible for the activation of the calcium channels [142].

A variety of GPCRs such as CB1 and CB2, orphan GPCRs such as GPR6, GPR3, GPR18, GPR12, and GPR55, along with adenosine, serotonin, and opioid receptors are found to be modulated by CBD [143]. Along with GPCRs, Voltage-gated calcium channels (VGCC) increases calcium influx due to constant hyperpolarization and activation of NMDAR [144], and these are implicated in the aging and neurodegeneration [145]. The higher concentration of calcium ions affects Calcineurin (CaN) and CaMKII signaling pathways and results in memory deficits and stimulation of long term depression in AD [146148]. Evidence represented by Ross et al. have shown that CBD acts as VGCC antagonist, and was able to fully inhibit T-type voltage-gated calcium channels (VGCCs), expressed from CaV3 gene [149]. Furthermore, CBD is also demonstrated to suppress L-type VGCC with IC 50 of $0.1 \mu \mathrm{M}$, where the effect was not mediated in a voltage-dependent manner [150]

Additionally, CBD also balances intracellular $\mathrm{Ca}^{2+}$ level, as the study found that $\mathrm{CBD}$ act as a transient receptor potential cation channel subfamily V1 (TRPV1) stimulant in HEK-TRPV1 cells, lacking any subtractive effects [151]. TRPV1 can act both as ion channel and receptor, and more prolonged activation of TRPV1 reduced pain through desensitization. TRPV1 can be activated upon any pain stimuli [152]. Some recent studies have indicated that TRPV1's channel unlocks upon activation, allowing ions to pass through the membrane from one side to another. Calcium passes over the pore systemically into the cell and activates various calcium-dependent pathways that finally lead to desensitization of the channel resulting in a reduction of inflammation pain [152-154]. Similarly, CBD exerts anti-hyperalgesic effects that may result from underlying peripheral and spinal activation via TRPV1 desensitization [155]. In vivo study shows that CBD derived TRPV1 agonistic activity can act as anti-inflammatory agents $[154,156]$. 


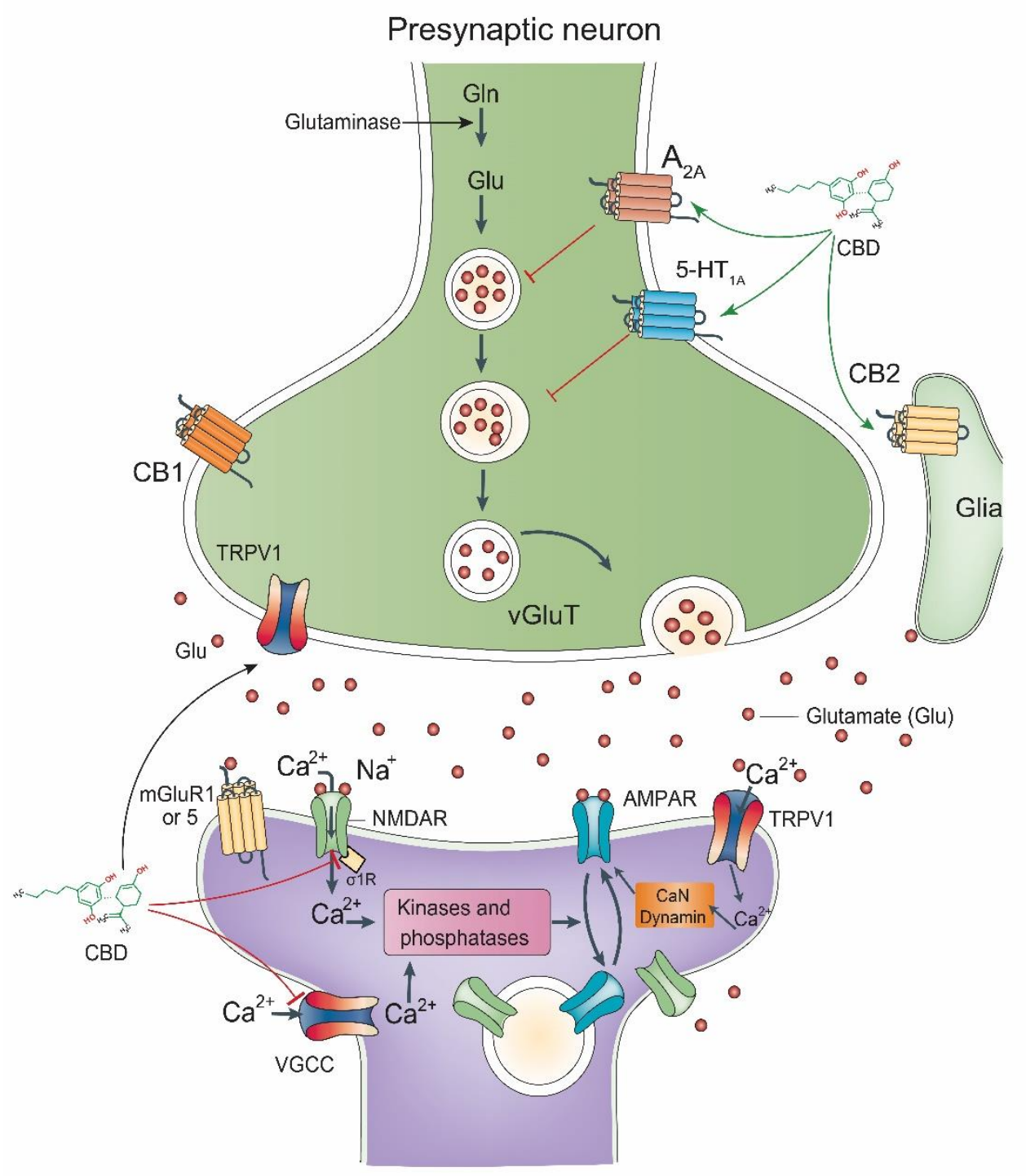

Postsynaptic neuron

Figure 3. Effect of $\mathrm{CBD}$ on $\mathrm{Ca}^{2+}$ dynamics in the synapse. In the presynaptic terminal, glutamine is converted to glutamic acid by glutaminase enzyme, and packaged to synaptic vesicles through vesicular glutamate transporters (vGluTs). The agonistic activity of $A_{2 A} R$ in the presynaptic terminal enhances glutamates release, whereas CBD is reported to acts as an antagonist and thus blocks glutamate release. CBD also indirectly regulate glutamate secretion by $5-\mathrm{HT}_{1 \mathrm{~A}}$ receptor [157]. Upon the release, glutamates bind with NMDAR, AMPARs and mGluR1/5 receptors, which causes $\mathrm{Ca}^{2+}$ influx, and activates intracellular messenger cascades. The $\sigma 1 R$ directly interacts with the cytosolic $C$-terminal region of the NMDA receptor, and regulate NMDAR activation. CBD inhibits the regulatory interaction between $\sigma 1 \mathrm{R}$ with NMDAR, and shows an opposite effect of NMDAR overactivity. Furthermore, CBD also acts as an antagonist of VGCC and TRPV1 antagonist and thus regulate intracellular calcium levels. CBD, Cannabidiol; $\mathrm{A}_{2 \mathrm{~A}}$, Adenosine 2A receptor; 5$\mathrm{HT}_{1 \mathrm{~A}}$, Serotonin-1A receptor; NMDAR, N-methyl-D-aspartate receptor; AMPARs, $\alpha$-amino-3-hydroxy-5methyl-4-isoxazolepropionic acid receptors; and mGluR1/5, metabotropic glutamate receptors 1/5; VGCC, 
Voltage-gated calcium channels; TRPV1, Transient receptor potential cation channel subfamily V member 1.

\section{CBD regulates proteostasis}

Proteostasis is known as the protein homeostasis network that regulates all aspects of the cellular proteome, from protein synthesis to degradation. As a part of this network, there are several signaling pathways, which are usually activated in response to misfolded protein and protein aggregation, are also known as quality control systems [158]. Once a protein is misfolded, chaperone control systems assist protein folding and disaggregation; however, if escaped, clearance systems are activated, leading aggregates into proteolytic degradation [10]. The clearance system is consisting of two main types of machinery, including the ubiquitin-proteasome system (UPS) and autophagy, where UPS functions in cytoplasm and nucleus, while autophagy only in the cytoplasm [159]. The degradation is directed by unfolded protein response (UPR), that follows either UPS or autophagy, which can be in the form of macroautophagy, including mitophagy, microautophagy, and chaperone-mediated autophagy (CMA) [160].

During the unfolded protein response, misfolded peptides are recruited by GRP78; eventually, ERS, IRE1 $\alpha$, PERK, and ATF6 dissociate from the luminal domains of UPRER sensors, which promotes parallel downstream signalings to reduce protein load by activating protein degradation and transport pathway. Lim et al. identified that CBD can alter ER morphology and initiate signaling cascades of PERK, ATF6, and IRE1, and thus elicits an endoplasmic reticulum (ER) stress response, which is not mediated by cannabinoid receptor [161]. In oligodendrocyte progenitor cells, CBD $(1 \mu \mathrm{M})$ decreased phosphorylation of eiF2 $\alpha$, enhanced Bcl-2 expression, and thus protected against OS, and similarly, those effects were not mediated through CB1, CB2, TRPV1 or PPAR- $\gamma$ receptors [76]. Moreover, a study on cadmium (Cd)-treated differentiated neuronal cells, showed that CBD $(1 \mu \mathrm{M})$ increased GRP78 upregulation and thus prevented $\mathrm{Cd}$ mediated ROS generation. Accordingly, CBD ameliorated Cd-induced neuronal injury, as well as prevent the cellular distribution of the cytochrome $C$, while down-regulated BAX [84]. CBD enhanced phosphorylation of PERK-chop and thus upregulated DR5 [162], where DR5/TRAIL-R2 signaling regulated UPR mediated cell death [163]. More recent studies showed that CBD regulated noxa ROS signaling pathway, resulting in the upregulation of IRE1 $\alpha$, PERK, Bip, GRP94, and CHOP in a dose-and timedependent manner [164]. Moreover, due to the upregulation of CHOP, CBD can regulate Smac, which inhibits XIAP, and thus plays a role against mitochondrial damage [165].

The autophagy is considered as the non-selective system, where aggregates are degraded by the lysosome, while UPS is target-specific protein for lysosomal degradation using ubiquitins like cargorecognition molecules and chaperons [166-168]. In this aspect, CBD is also reported to induce autophagy, appeared in several studies. The report represented by Shrivastava et al. showed that CBD could regulate autophagy by inhibiting AKT and mTOR signaling pathway by downregulating cyclin D1 and reducing the phosphorylation of mTOR and 4EBP1 (Figure 4) [169]. Similarly, CBD was also shown to induce autophagy in vivo, and prevented alcohol-mediated autophagy inhibition, while downregulating JNK MAPK pathway and OS [170]. Supporting this finding, Giacoppo and colleagues observed that CBD regulated in PI3K/Akt/mTOR pathway Encephalomyelitis (EAE) MS model and also promotes neuroprotection by inhibiting JNK and p38 MAP kinases [171]. Hossein Zadeh et al. showed that repeated treatment of $0.100 \mathrm{ng}$ CBD as an intracerebroventricular injection in epileptic rats induce several autophagy markers such as conjugation of Atg5/12, Atg7, Atg12, and LC3II/LC3I expression, especially in hippocampal cells, confirming protective effect in epilepsy followed by autophagy pathway [172]. A study using Glioma stem-like cells suggested that induction of autophagy by CBD was triggered by activating transient receptor potential vanilloid-2 (TRPV2) [173,174], and thus increased response to radiosensitivity [175]. 
Although the precise mechanisms of CBD remain to be further investigated, it is unlikely that activation of autophagy is mediated through CB1 receptor [176], which is localized in lysosomal compartments [177]. However, a very recent study showed that CBD could potentially inhibit BACH1 [81], which acts as a repressor of p62 expression, a component that involved in selective autophagy [178].

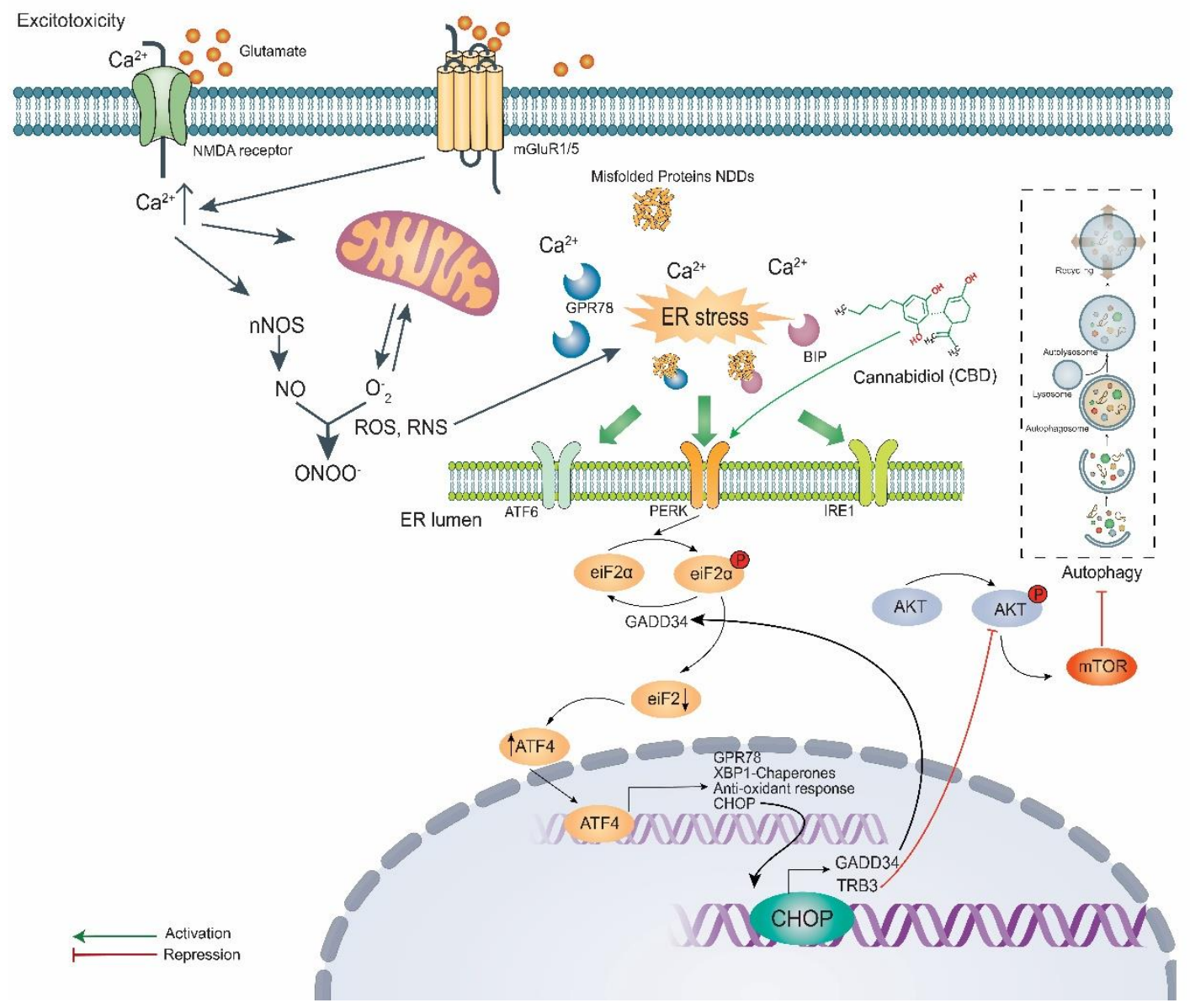

Figure 4. Proposed mechanism of CBD effects in the ER stress-related signaling pathway. In excitatory toxicity, the excessive glutamates overactive NMDAR function, which leads to Ca2+ influx, in turn, cause NO production. The ER stress is mediated by NO as well as by misfolded proteins, where misfolded protein bind to BIP and GPR78 and activates UPR, which comprises PERK, IRE1, and ATF6 pathways. Among them, CBD may regulate the PERK signaling pathway, and by doing so, it upregulates ATF4 mediated genes transcription, including CHOP and GRP78. The CHOP, which is a transcription factor, enhances TRB3 and GADD34 expressions. TRB3 inhibits AKT phosphorylation that subsequently inhibits mTORC1, and thereby promotes autophagy. The CHOP mediated gene transcription also promotes apoptosis in prolonged ER stress, when protein misfolding is not resolved, whereas, GADD34 acts as a negative regulator of eIF2 $\alpha$ phosphorylation and hence halts pro-apoptotic signaling pathways. UPR, unfolded protein response; ER stress, endoplasmic reticulum stress, NMDAR, N-methyl-Daspartate receptor; NO, Nitric oxide; GRP78/BIP, Immunoglobulin heavy-chainbinding protein; PERK, PRKR-like ER kinase; eIF2 $\alpha$, eukaryotic translation initiation factor $2 \alpha$, ATF6, activating transcription factor $6 \alpha$; ATF4, activating transcription factor 4, CHOP, C/EBP homologous protein; GADD34, growth arrest and DNA damage-inducible protein 34 . 


\section{Cannabidiol as a treatment of neurodegenerative disorders}

\section{Huntington's disease (HD)}

Huntington Disease is a lethal, progressive neurodegenerative disorder, featured by motor impairment, cognitive deficits, and behavioral shortages that occur due to mutation of the huntingtin proteins [179]. The major pathogenic mechanisms underlying the neuronal dysfunction and death in HD include transcriptional dysregulation, altered proteostasis, mitochondrial dysfunction [180]. Impaired huntingtin proteins are also responsible for enhancing OS, dopamine toxicity, metabolic impairment, excitotoxicity, apoptosis, and autophagy [181]. The oxidative and inflammatory death of neurons can be reduced by activating anti-inflammatory PPAR- $\gamma$ signaling [182]. For preclinical studies, there are many compounds such as histone deacetylase inhibitors, coenzyme Q10, minocycline, unsaturated fatty acids that have been tested to inhibit HD. However, the finding was not significant [183]. The application of CBD alone or, in combination with $\triangle 9$-THC (tetrahydrocannabinol), showed much efficiency in the preclinical evaluation of several experimental models of HD [184,185]. Abdel-Salam et al. found that CBD reduced neuroinflammation and microglial cell activation in HD models [186]. Da Silva et al. suggested that CBD has iron-induced anti-apoptotic effects on cognitive decline model system [187]. CBD also decreased the expression of HD biomarkers such as GPR3, GPR6, and GPR12, acting as an inverse agonist [188,189], while in another experiment, CBD showed neuroprotective activity in a rat model of HD [190]. A licensed drug Sativex ${ }^{\circledR}$ (a combination of $\Delta(9)$-THC and CBD) showed positive effects against HD [191]. Valdeolivas et al. also found that Sativex ${ }^{\circledR}$ treatment reduced basal ganglial metabolism in R6/2 transgenic HD mice model [192]. Another study conducted by Moreno et al., however, claimed that treatment with sativex® in HD patients showed no changes in biomarkers of HD and no symptomatic adverse effects [193].

\section{Alzheimer's disease $(A D)$}

Alzheimer's disease (AD) is a chronic, neurodegenerative disorder which is characterized by the intra-neuronal neurofibrillary tangles, extracellular senile plaques, and neuronal atrophy [194]. Senile plaques are surrounded by dystrophic neurites, microglia, and astrocytes [195]. In AD, it is prominent to clear the aggregation of $\beta$-amyloid, and here microglia plays a vital role in the clearance of $A \beta[196,197]$. Evidence showed that CBD has a potential impact on AD-associated pathology [74,198]. Giuseppe Esposito et al. demonstrated that CBD promotes hippocampal neurogenesis through the association with PPAR- $\gamma$, prevented reactive gliosis, reduced $\mathrm{A} \beta$ induced inflammation by lowering pro-inflammatory cytokines and thus neurodegeneration in an AD rat model [40]. These neuroprotective roles of CBD against A $\beta$-induced toxicity are known to be attributed to its antioxidant and anti-inflammatory activities. An in-vivo experiment conducted by Watt \& Karl showed that CBD ameliorated the cognitive deficits in a double transgenic AD mouse [199]. Some studies demonstrated that CBD enhanced APP ubiquitination, which subsequently decreased $A \beta$ plaques by inhibiting the hyperphosphorylation of tau [200]. It was correlated with the decreased expression of Wnt signaling inhibitor p-GSK-3 $\beta$. It is also evident that CBD decreases mitochondrial dysfunction and the production of reactive oxygen species through the activation of PPAR$\gamma$ and suppressing pro-inflammatory signaling in AD [201]. Singh \& Abraham proposed that CBD inhibits reactive gliosis occurred by $\mathrm{A} \beta$, which is an effective technique to slow down the growth of $\mathrm{AD}$ [202]. The activation of CB2 decreases the microglia activity and the production of inflammatory cytokines [203]. Harris et al. suggested that through the clearance of $A \beta, C B 2$ agonists could lower $A \beta$ plaque, whereas $\mathrm{CBD}$ act as an agonist [204]. Moreover, the toxicity of A $\beta$ diminishes PI3K/Akt signaling, and interestingly, CBD down regulates GSK-3 $\beta$ expression and promotes PI3K/Akt signaling [171,200]. CBD also reduces the expression of $\beta$ - and $\gamma$-secretase enzyme, which eventually decreases $A \beta$ production [200]. 
Parkinson's disease (PD) is a progressive neurodegenerative disorder that is characterized by the lack of dopamine, deposition of $\alpha$-synuclein, and the gradual loss of dopaminergic neurons [205,206]. The symptoms of PD in the early stages are shaking, gait abnormality, spasticity, and slow thinking capacity. The pathogenesis of PD is associated with neuroinflammation and oxidative damage to the neurons [207]. In PD rodent models, CBD influenced the levels of SOD mRNA, increased the expression of antioxidant zinc homeostasis gene, and reduced OS [76,208,209]. A series of the study verified the activity of CBD in PD patients, where they showed CBD ameliorate the quality of life, reduced sleep disorder, provide antidepressant and anxiolytic activity [210,211]. The effects of CBD in PD have also been validated in animal models such as 6-hydroxydopamine-lesioned PD rats in which the antioxidant properties of CBD protected the eventual degeneration of nigrostriatal dopaminergic neurons [209,212,213]. Lotan et al. suggested that CBD lowered gliosis, free radicals, amyloid, tau deposition, iNOS, oxidized-GSH, and influenced autophagy, and complex IV in PD mouse model preclinical study [214]. In an experimental trial, the administration of CBD reduced the tremor amplitude in PD patients [215], and CBD could be a promising drug to treat non-motor symptoms of PD [216]. Fernanda F. Peres et al. showed that CBD could reduce reserpine-induced motor and cognitive impairment in AD model rats [217].

Furthermore, previous results from several clinical trials suggested that CBD is beneficial while conjugating with $\triangle(9)$-THC in alleviating symptoms linked to PD like dystonia but not in symptoms such as tremor [218-220]. Again, the promising neuroprotective effects of CBD have been observed in vitro studies on PD models [221]. Santos et al. reported the CBD-mediated neuroprotection against $\mathrm{MPP}^{+}$ induced neurotoxicity in PC12 that involved induction of neurite differentiation, expression of synaptic (synaptophysin and synapsin I) and axonal (GAP-43) proteins and the activation of tropomyosin receptor kinase A (TrkA) receptors [221].

\section{Multiple sclerosis (MS)}

Multiple sclerosis (MS) is an inflammatory demyelinating disease, which destroys the spinal cord and brain nerve cells of the CNS [222], and considered to affect the young and middle-aged individuals [223]. It impedes signal transmission with the following symptoms; trouble with sensation or coordination, blindness in one eye, double vision, muscle weakness, and bladder dysfunction [224,225]. The downregulation of PI3K/AKT/mTOR pathway is known to be associated with the pathogenesis of MS [226]. However, several studies suggested that MS disease has complicated pathophysiology, and immunotherapy was not so responsive in the progressive stages of MS [227-229]. The previous study indicated that the use of cannabis reduces MS symptoms [230]. The cannabis-based compounds such as CBD was used to alleviate pain and spasticity in MS [231,232]. In an EAE model of MS, Elliott et al., found that CBD reduced T cell penetration, IFN $\gamma$, and IL-17 and increased MDSCs (myeloid-derived suppressor cells) with attenuation of EAE [233]. Kozela et al. found that the pathogenic activity of Th17 cells was decreased after CBD treatment [102].

Moreover, CBD reduced microglial activity, leukocyte homing, and inflammation in TMEV-IDD and EAE model. Besides, CBD reduced blood leukocyte migration by reducing VCAM-1, CCL2 and CCL5, TNF $\alpha /$ IL-1 $\beta$, and microglial activation [39]. Giacoppo et al. observed that phosphorylation of PI3K, Akt, and mTOR was significantly increased together with BDNF expression and reduced the expression of proinflammatory cytokine IFN- $\gamma$ and IL-17 after CBD treatment. CBD was also acted as an antagonist to JNK and p38 MAP kinases [171]. Indeed, THC combination with CBD as an oromucosal spray (Sativex®) was established as a potential therapeutic agent for mitigating MS symptoms [234]. The combination of THC: CBD oromucosal spray was able to decline MS spasticity [235].

Furthermore, the CBD/THC transdermal treatment (Sativex R) has been proven to be useful to relieve pain associated with MS in a new study of cannabis-based therapy for neuropathic pain [236]. Further research reported that the CBD/THC combination is capable of reducing sleep and pain disorders and is 
broadly accepted in patients with MS-related chronic neuropathic pain [237]. Croxford al., reported that CBD could be more effective in neuroprotection that in immunosuppression. Moreover, a substantial reduction of urinary pressure, a decrease of bladder control, volume, and excessive urination frequency have been demonstrated in combining THC/CBD treatment [238]. Overall, the pharmacological properties of THC/CBD may provide an overview of its clinical efficacy and tolerability in spasticity and other MSrelated symptoms [239].

\section{Prion Diseases}

Prion diseases occur due to the abnormal assembly of the protease-resistant prion protein (PrPres) aggregates on the surface of many cells forming clump in the brain, causing brain damage, which split the typical tissue structure. As vacuole forms in the neurons, some holes are formed in the tissue like spongy architecture [240,241]. The PrPres aggregates cause extensive ER stress, which subsequently disrupts $\mathrm{Ca}^{2+}$ homeostasis. The maintenance of $\mathrm{Ca}^{2+}$ homeostasis is an essential event for continuing neuronal signaling $\mathrm{Ca}^{2+}$ released in the cytoplasm when cells are exposed to the misfolded prion proteins [242-244]. Mecha et al. found that CBD attenuated ER stress and induced an anti-apoptotic pathway [76]. Cannabinoids, including CBD, have shown to protect against brain injury. PrPres assembly was inhibited by the treatment of CBD in mouse and sheep scrapie-infected cells. Peripheral CBD injection restricted PrPres cerebral accumulation and increased the lifespan of the infected mice after intraperitoneal infection [241].

Additionally, it has been found that neurons trigger microglial cell migration in response to PrPres exposure [245]. CBD reduced neurotoxic impacts of PrPres, and microglial cell migration is activated by affected PrPres in a concentration-dependent manner [241]. Thus, during the prion infection, CBD may tend to prevent neurons in the diverse stages of the neurodegenerative treatment against the multiple molecular and cellular influences. As a corollary, CBD could be a favorable drug showing anti-prion properties, which to be used in prion disease, but it requires high concentration of CBD to achieve its survival efficacy [241].

\section{Amyotrophic Lateral Sclerosis (ALS)}

Amyotrophic lateral sclerosis (ALS) is a progressive and lethal neurodegenerative disease, which affects both lower and upper motor neurons, resulting in spasticity, weakness, and, lastly, death due to respiratory collapse [246,247]. Although the pathobiology of ALS much remains unknown, like other NDDs, the pathogenic mechanisms, including OS, inflammation, excitotoxicity, mitochondrial dysfunction, and protein misfolding, are also known to be involved in ALS [28,248]. Having antioxidant, anti-inflammatory, and neuroprotective potentials, CBD has shown to attenuate ALS pathology in various experimental evidence $[28,249]$.

As an in vitro ALS model, treatment of human gingiva-derived mesenchymal stromal cells with CBD modulated the expression of genes associated with ALS pathologies, such as OS, mitochondrial dysfunction, and excitotoxicity [250]. CBD upregulated the expression of Nrf2, mitochondrial respiration maintenance genes, i.e., SDHC1, NDUFC2, and NDUFV3, and downregulated cell death-inducing genes, i.e., CABIN1, PPP3CC, HTRA2, and TARBP2. The evidence that the expression of CB2 receptors has been reported in activated microglia from the spinal cord of human ALS patients suggests the possibility that CBD, a CB2 agonist, may provide therapeutic impacts in ALS at the clinical level. A recent phase 2 trial (CANALS study) demonstrated that THC: CBD was able to lessen the spasticity in ALS [251]. Finally, treatment satisfaction by the patients has studied in which $84 \%$ of patients experienced positive effects on 
THC: CBD treatment in ALS [252]. A randomized, double-blind, placebo-controlled trial evaluating the efficacy of CBD oil (CBD:THC $=25:<2$ ) has shown to slow the ALS progression [253].s 


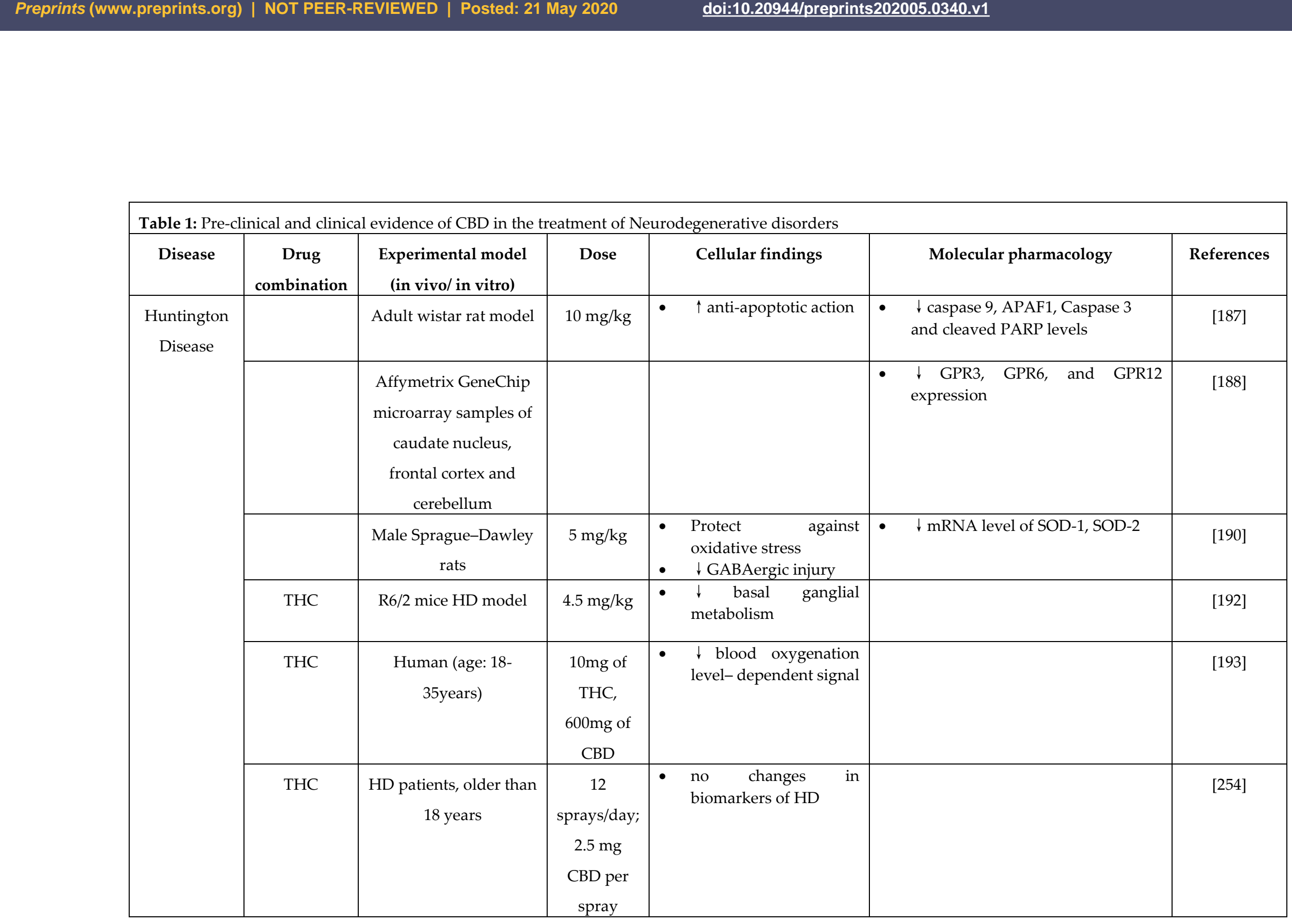




\begin{tabular}{|c|c|c|c|c|c|c|}
\hline \multirow{9}{*}{$\begin{array}{l}\text { Alzheimer's } \\
\text { disease }\end{array}$} & & PC12 neuronal cells & & $\begin{array}{l}-\quad \downarrow \text { tau } \\
\text { hyperphosphorylation }\end{array}$ & $\begin{array}{ll}\text { - } & \uparrow \text { Wnt } / \beta \text {-catenin pathway } \\
\text { - } & \downarrow \text { p-GSK3 } \beta\end{array}$ & [74] \\
\hline & & $\begin{array}{l}\text { Mice inoculated with } \\
\text { human A } \beta 42 \text { peptide }\end{array}$ & $\begin{array}{l}2.5,10 \\
\mathrm{mg} / \mathrm{kg}\end{array}$ & $\begin{array}{ll}\text { - } & \text { Protect against } \\
& \text { oxidative stress } \\
\text { - } & \downarrow \text { reactive glisosis }\end{array}$ & $\begin{array}{ll}\bullet & \downarrow \text { iNOS } \\
\bullet & \downarrow \text { IL-1 } \beta \text { expression }\end{array}$ & [198] \\
\hline & & $\begin{array}{l}\text { Adult male Sprague- } \\
\text { Dawley rat model }\end{array}$ & & $\begin{array}{l}\text { - } \quad \downarrow \mathrm{A} \beta \text { induced } \\
\text { inflammation } \\
\text { - } \quad \downarrow \text { reactive gliosis }\end{array}$ & $\begin{array}{ll}\cdot & \uparrow \text { of PPAR- } \gamma \\
\cdot & \downarrow \text { NO, TNF } \alpha, \text { and IL-1 } \beta \text { expression }\end{array}$ & [40] \\
\hline & & PC12 neuronal cells & & $\begin{array}{ll}\text { - } & \text { Protect against } \\
\text { - } & \text { oxidative stress } \\
& \downarrow \mathrm{A} \beta \text { neurotoxicity }\end{array}$ & $\begin{array}{ll}\cdot & \downarrow \text { ROS production } \\
\text { - } & \downarrow \text { lipid peroxidation, caspase } 3 \\
\text { level }\end{array}$ & [75] \\
\hline & & SH-SY5YAPP+ Cells & & $\begin{array}{l}\text { - } \quad \uparrow \text { APP ubiquination } \\
\text { - } \quad \uparrow \text { cell viability }\end{array}$ & - $\quad \uparrow$ PPAR- $\gamma$ activation & [255] \\
\hline & & $\begin{array}{c}\text { Gingiva derived } \\
\text { mesenchymal stem } \\
\text { cells }\end{array}$ & $5 \mu \mathrm{M}$ & $\begin{array}{l}\text { - } \quad \downarrow \text { tau } \\
\text { hyperphosphorylation } \\
\text { - } \quad \downarrow \text { A } \beta \text { production }\end{array}$ & $\begin{array}{ll}\cdot & \uparrow \text { PI3K/Akt signaling cascade } \\
- & \downarrow \text { GSK3 } \beta, \text { CDK5, DYRK1A, } \\
\text { CAMK2A, and the MAPKs } \\
\text { (MAPK1, MAPK12, and MAPK14) } \\
\text { expression }\end{array}$ & [200] \\
\hline & & $\begin{array}{l}\text { Mice intraventricularly } \\
\text { injected with fibrillar } \\
\text { A } \beta\end{array}$ & $20 \mathrm{mg} / \mathrm{kg}$ & - $\quad \downarrow$ microglial activation & & [256] \\
\hline & THC & $\begin{array}{l}\text { Young APPxPS1 } \\
\text { transgenic mice }\end{array}$ & $\begin{array}{c}10 \mathrm{~mL} / \mathrm{kg} \\
(0.75 \\
\mathrm{mg} / \mathrm{kg} \\
\text { each })\end{array}$ & $\begin{array}{ll}- & \downarrow \text { A } \beta 42 \text { peptide levels } \\
- & \downarrow \text { astrogliosis and } \\
& \text { microgliosis }\end{array}$ & $\begin{array}{l}\text { - } \quad \uparrow \text { Mapk3 and Wnt16 sig-705naling } \\
\text { pathways } \\
\text { - } \quad \downarrow \text { ERK1 phosphorylation }\end{array}$ & [257] \\
\hline & THC & $\begin{array}{l}\text { Aged APPxPS1 } \\
\text { transgenic mice }\end{array}$ & $\begin{array}{c}10 \mathrm{~mL} / \mathrm{kg} \\
(0.75 \\
\mathrm{mg} / \mathrm{kg} \\
\text { each })\end{array}$ & $\begin{array}{ll}\text { - } & \downarrow \text { cognitive deficits } \\
- & \downarrow \text { glial reactivity }\end{array}$ & $\begin{array}{ll}\text { - } & \downarrow \text { GluR2/3 expression } \\
\text { - } & \uparrow \text { GABA-A R } \alpha 1 \text { expression }\end{array}$ & [258] \\
\hline
\end{tabular}




\begin{tabular}{|c|c|c|c|c|c|c|}
\hline & THC & $\begin{array}{l}\text { Transgenic tauopathy } \\
\text { mouse model }\end{array}$ & $\begin{array}{c}4.63 \mathrm{mg} / \mathrm{kg} \\
(\mathrm{CBD}: 1.5 \\
\mathrm{mg} / \mathrm{kg})\end{array}$ & $\begin{array}{ll}- & \text { Protect against } \\
& \text { oxidative stress } \\
- & \downarrow \text { astrogliosis and } \\
& \text { microgliosis }\end{array}$ & $\begin{array}{ll}- & \downarrow \text { iNOS level } \\
- & \uparrow \text { complex IV expression }\end{array}$ & [259] \\
\hline \multirow{8}{*}{$\begin{array}{l}\text { Parkinson's } \\
\text { disease }\end{array}$} & & 6-OHDA/rat & $3 \mathrm{mg} / \mathrm{kg}$ & $\begin{array}{ll}- & \downarrow \text { oxidative stress } \\
- & \downarrow \text { glial cell activation }\end{array}$ & $\begin{array}{ll}- & \downarrow \text { ROS } \\
\text { - } & \uparrow \text { mRNA levels of } \mathrm{Cu}, \mathrm{Zn}-\mathrm{SOD}\end{array}$ & [209] \\
\hline & & 6-OHDA/rat & $3 \mathrm{mg} / \mathrm{kg}$ & $\begin{array}{l}-\quad \uparrow \text { dopaminergic } \\
\text { transmission }\end{array}$ & $\begin{array}{l}-\quad \downarrow \text { mRNA levels of tyrosine } \\
\text { hydroxylase }\end{array}$ & [212] \\
\hline & & $\begin{array}{l}\text { In vitro retinoic acid } \\
\text { (RA)-differentiated } \\
\text { neuroblastoma SH- } \\
\text { SY5Y cells with the } \\
\text { toxin MPP+ }\end{array}$ & $10 \mu \mathrm{M}$ & - $\quad \downarrow$ loss of cell viability & $\begin{array}{ll} & \uparrow \text { ERK and AKT/mTOR pathway } \\
\text { - } \quad \text { Downregulate PARP-1 levels }\end{array}$ & [215] \\
\hline & & $\begin{array}{c}\text { Reserpine-induced } \\
\text { Mice model } \\
\end{array}$ & $\begin{array}{c}0.5-5 \\
\mathrm{mg} / \mathrm{kg}\end{array}$ & $\begin{array}{l}\text { - } \quad \downarrow \text { catalepsy, memory } \\
\text { deficits }\end{array}$ & - $\quad \uparrow$ 5-HT1A receptor activation & [217] \\
\hline & & $\begin{array}{l}\text { Human (age: }>45 \\
\text { years); placebo } \\
\text { controlled trials }\end{array}$ & $\begin{array}{c}75 \mathrm{mg} / \mathrm{kg} \\
\text { and } 300 \\
\mathrm{mg} / \mathrm{kg} ; 6 \\
\text { week }\end{array}$ & $\begin{array}{l}\text { - } \quad \downarrow \text { REM related sleep } \\
\text { behavior disorder } \\
\text { - } \quad \uparrow \text { antidepressant and } \\
\text { anxiolytic activity }\end{array}$ & & [210] \\
\hline & & Male swiss mice & $\begin{array}{l}30,60 \\
\mathrm{mg} / \mathrm{kg}\end{array}$ & - $\quad \downarrow$ catalepsy & $\begin{array}{ll}\text { - } & \downarrow \text { c-Fos protein expression } \\
\text { - } & \uparrow \text { 5-HT1A receptor activation }\end{array}$ & [260]. \\
\hline & & PC12 and SH-SY5Y cell & $\begin{array}{l}1,5,10,25 \\
\text { and } 50 \mu \mathrm{M}\end{array}$ & - $\quad \uparrow$ cell viability & $\begin{array}{l}\text { - } \\
-\quad \uparrow \text { TrkA receptors } \\
\quad \quad \text { GAP-43, synaptophysin and } \\
\text { synapsin I expression }\end{array}$ & [221] \\
\hline & & $\begin{array}{l}\text { Experimental } \\
\text { autoimmune }\end{array}$ & $215 \mathrm{mg} / \mathrm{kg}$ & $\begin{array}{lc} & \downarrow \text { disability and } \\
& \text { disability progression } \\
\text { - } & \downarrow \text { pain and spasticity }\end{array}$ & $\begin{array}{ll}\bullet & \downarrow \text { TNF- } \alpha \text { production } \\
\bullet & \uparrow \text { BDNF gene expression }\end{array}$ & [261] \\
\hline
\end{tabular}




\begin{tabular}{|c|c|c|c|c|c|c|}
\hline \multirow[t]{7}{*}{$\begin{array}{c}\text { Multiple } \\
\text { Sclerosis } \\
\text { disease }\end{array}$} & & $\begin{array}{c}\text { encephalomyelitis } \\
\text { (EAE)-induced Rat } \\
\text { model }\end{array}$ & & & & \\
\hline & & $\begin{array}{c}\text { Experimental } \\
\text { autoimmune } \\
\text { encephalomyelitis } \\
\text { (EAE)-induced Mice } \\
\text { model } \\
\end{array}$ & $20 \mathrm{mg} / \mathrm{kg}$ & $\begin{array}{l}\text { - } \quad \uparrow \text { myeloid-derived } \\
\text { suppressor cell } \\
\quad \downarrow \text { cellular infiltration } \\
\text { and tissue damage }\end{array}$ & $\begin{array}{ll}- & \downarrow \text { T cell penetration } \\
- & \downarrow \text { IFN } \gamma \text { and IL-17 levels }\end{array}$ & [233] \\
\hline & & $\begin{array}{c}\text { in vitromodel of } \\
\text { stimulated TMOGcells } \\
\text { co-cultured with } \\
\text { spleen-derived CD19+B } \\
\text { cells and other } \\
\text { accessory CD4+cells }\end{array}$ & $5 \mu \mathrm{M}$ & 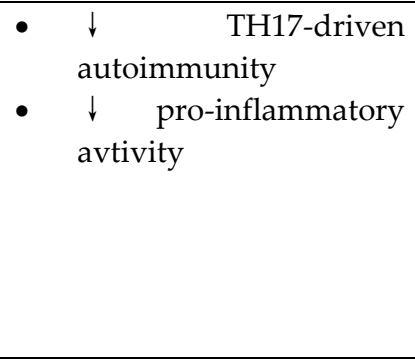 & $\begin{array}{ll} & \uparrow \text { of CD69 and LAG3 levels } \\
- & \downarrow \text { CD25 and CD69 levels } \\
\text { - } & \uparrow \text { EGR2 transcription } \\
\text { - } & \text { Reduce Akt activation }\end{array}$ & [102] \\
\hline & & $\begin{array}{l}\text { TMEV-IDD susceptible } \\
\text { Mice model }\end{array}$ & $5 \mathrm{mg} / \mathrm{kg}$ & $\begin{array}{lcc}- & \downarrow & \text { leukocyte } \\
& \text { transmigration } \\
\text { - } & \downarrow \text { microglial activation }\end{array}$ & $\begin{array}{l}\text { - } \quad \downarrow \text { VCAM-1, CCL2 and CCL5 } \\
\text { expression } \\
\text { - } \quad \downarrow \text { IL-1 } \beta \text { levels }\end{array}$ & [39] \\
\hline & & $\begin{array}{c}\text { Experimental } \\
\text { autoimmune } \\
\text { encephalomyelitis } \\
\text { (EAE)-induced Mice } \\
\text { model } \\
\end{array}$ & $10 \mathrm{mg} / \mathrm{kg}$ & $\begin{array}{ll}\bullet & \uparrow \text { neuronal survival } \\
- & \downarrow \text { inflammation } \\
- & \downarrow \text { JNK and p38 MAP } \\
& \text { kinases }\end{array}$ & $\begin{array}{ll} & \downarrow \text { PISK/Akt/mTOR pathway } \\
\text { - } & \uparrow \text { BNDF level } \\
\bullet & \uparrow \text { PPAR- } \gamma \\
\text { - } & \text { Decrease IFN } \gamma \text { and IL-17 levels }\end{array}$ & [171] \\
\hline & THC & $\begin{array}{l}\text { Human (age: }>50 \\
\text { years); placebo } \\
\text { controlled trials }\end{array}$ & & - $\quad \downarrow$ pain and spasticity & & [235] \\
\hline & THC & $\begin{array}{c}\text { Human (age: } \geq 18 \text { years); } \\
\text { placebo-controlled } \\
\text { trials }\end{array}$ & & - $\quad \downarrow$ neuropathic pain & & [236] \\
\hline
\end{tabular}




\begin{tabular}{|c|c|c|c|c|c|c|}
\hline & THC & $\begin{array}{c}\text { Human (age: } 18-65 \\
\text { years) }\end{array}$ & $\begin{array}{c}2.5 \mathrm{mg} \text { of } \\
\text { each per } \\
\text { spray }\end{array}$ & $\begin{array}{ll}- & \downarrow \text { pain, spasticity } \\
- & \uparrow \text { quality of sleep } \\
- & \downarrow \text { excessive urination } \\
& \text { frequency }\end{array}$ & & [262] \\
\hline Prion disease & & $\begin{array}{c}\text { mice and sheep } \\
\text { scrapie-infected cells }\end{array}$ & $5 \mu \mathrm{M}$ & $\begin{array}{ll}- & \downarrow \text { PrPres accumulation } \\
- & \downarrow \text { PrPre-induced } \\
& \text { microglial cell } \\
& \text { migration }\end{array}$ & - $\downarrow \downarrow$ NMDA receptor action & [241] \\
\hline \multirow[t]{2}{*}{$\begin{array}{l}\text { Amyotrophic } \\
\text { lateral } \\
\text { sclerosis } \\
\text { (ALS) }\end{array}$} & & $\begin{array}{l}\text { human gingiva-derived } \\
\text { mesenchymal stromal } \\
\text { cells (hGMSCs) }\end{array}$ & & $\begin{array}{ll}- & \text { Control oxidative } \\
\text { stress } \\
\text { - } \\
\text { Control mitochondrial } \\
\text { dysunction }\end{array}$ & $\begin{array}{ll}\cdot & \uparrow \text { NFE2L2, TRAP1 gene expression } \\
- & \uparrow \text { SDHC1, NDUFC2, and NDUFV3 } \\
\text { gene expression } \\
\quad \downarrow \text { CABIN1, PPP3CC, HTRA2, and } \\
\text { TARBP2 gene } \\
\text { expression }\end{array}$ & [250] \\
\hline & THC & $\begin{array}{l}\text { Human (age:18-80 } \\
\text { years); placebo- } \\
\text { controlled trials }\end{array}$ & $\begin{array}{l}100 \mu \mathrm{L}(2 \cdot 7 \\
\mathrm{mgTHC} \\
\text { and } 2 \cdot 5 \mathrm{mg} \\
\quad \mathrm{CBD})\end{array}$ & - $\quad \downarrow$ spasticity & $\begin{array}{ll}\cdot & \downarrow \text { presynaptic } \mathrm{Ca}^{2+} \text { influx } \\
- & \downarrow \text { glutamatergic neurotransmitters } \\
& \text { release }\end{array}$ & [251] \\
\hline
\end{tabular}




\section{Concluding remarks and future perspectives}

OS and neuroinflammation affect the integrity of the proteostasis network and thereby play a pivotal role in the pathogenesis of neurodegenerative diseases by affecting the integrity of the proteostasis network. Because of the involvement of the endocannabinoid systems in OS modulation, CBD may count as an interesting molecule, as it is has shown to provide antioxidant and antiinflammatory effects in various preclinical models. However, the precise mechanisms of CBD is remained to elucidate, especially in the activation of protein aggregates clearance systems.

Although multidirectional studies provide clear evidence of CBD mediated autophagy induction, however, neuronal system-based studies are limited, and the molecular pharmacology is also poorly understood. Furthermore, studies showed that autophagy as a double edge sword might induce either death or survival mechanism, suggesting the need for future study, as the phenomenon of the activation and activating receptors are unlike with different cell types.

Recently, Scott et al. showed that CBD treatment modulated HSPs expression, notably upregulated HSP70 and HSP90 in glioma cell lines [263]. Substantial evidence highlighted the critical roles of HSP70 and HSP90 in the quality control and clearance of the misfolded and aggregated proteins by the ubiquitin-proteasome system and chaperone machinery [264]. Additional observation by Rodríguez-Muñoz et al. stated that CBD act as an antagonist of $\sigma 1 \mathrm{R}$, which has been identified as a master regulator of proteostasis system [265]. The antagonist of $\sigma 1 \mathrm{R}$ is responsible for the induction of unfolded protein response and autophagy in dose dependent manner [266], and also modulate HSP70 regulations [267]. Furthermore, CBD promoted cytosolic degradation of BACH1, which, according to another study, is mediated through the ubiquitin-proteasome system [268]. Thus these findings provide a clue that $\mathrm{CBD}$ can regulate both the ubiquitin-proteasome system and chaperone machinery. Maintenance of intracellular $\mathrm{Ca}^{2+}$ homeostasis is an essential function of ER, if disturb, stress in ER induced that endorsed misfolded protein accumulation. Since CBD regulates both glutamate release and NMDAR activation, it can protect neurons from glutamate excitotoxicity and ER stress-mediated injuries. Although several comprehensive reviews $[30,95,97,114]$ suggest that CBD regulation in OS and inflammations is likely to mediate by CB1, CB2, TRPV1 or PPAR$\gamma$ receptors, but none of the receptors is reported to implicate when studies showed CBD effect in mitigating OS in ER stress response [269]. Furthermore, the molecular insights into the activation and regulation of PERK, IRE1, and ATF6 pathways are still unclear. Thus understanding the ROS regulation by $\mathrm{CBD}$ is still far away and deserves more studies, especially in neuronal models.

As represented in Table 1, CBD and its combination with THC provide therapeutic benefits for various neurodegenerative disorders. However, most of the findings were based on short term effects, and the preclinical studies barely used transgenic models, and future studies should, therefore, be designed to analyze long term effects analysis, as well as using transgenic mouse models. Although studies discussed in this review suggest therapeutic benefits of combination therapy with $\mathrm{CBD}$, care must be taken when choosing drug combination, as the study showed induction of serum ALT and AST, and also inactivation of cytochrome P450 3A and P450 2C in CBD therapy [270]. Furthermore, combination therapy may facilitate the drug interaction that could be antagonistic to reduce the pharmacological efficacy of the compounds.

Finally, this review suggests a "proof of principle" of CBD regulation in proteostasis network, especially in the activation of protein clearance systems, that would offer a therapeutic window in protein aggregates clearance and thus to reverse proteinopathies. The discussed studies in this communication are promising; however, they provide preliminary data. Therefore, we suggest advanced research to investigate the CBD effect in protein aggregates clearance on the various disease model of neurodegeneration.

Author Contributions: R.D. contributes to review designing, manuscript writing, table, and figure mapping. I.J, M.C.A., Y.A.M., and S.M. contribute to manuscript writing, revision, and summary table preparation. M.A.H., B.T., D.F.O., and H.J.C. contribute to manuscript writing and revision. I.S.M. contributes to review planning and supervision and manuscript revision. All the authors read and approved this manuscript. 
Acknowledgments : $\quad$ This work was supported by Korea Research Fellowship Program (grant No. 2018H1D3A1A01074712) to MAH, and by the Basic Science Research Program (grant number 2018R1A2B6002232) to ISM through the National Research Foundation of Korea (NRF) NRF funded by the Ministry of Science, ICT and Future Planning.

Competing Interests: Authors declare no competing interests.

\section{References}

1. Menzies, F.M.; Fleming, A.; Rubinsztein, D.C. Compromised autophagy and neurodegenerative diseases. Nature Reviews Neuroscience 2015, 16, 345-357, doi:10.1038/nrn3961.

2. Sarkar, S. Regulation of autophagy by mTOR-dependent and mTOR-independent pathways: autophagy dysfunction in neurodegenerative diseases and therapeutic application of autophagy enhancers. Biochem Soc Trans 2013, 41, 1103-1130, doi:10.1042/BST20130134 \%J Biochemical Society Transactions.

3. Skovronsky, D.M.; Lee, V.M.Y.; Trojanowski, J.Q. Neurodegenerative diseases: new concepts of pathogenesis and their therapeutic implications. Annu. Rev. Pathol. Mech. Dis. 2006, 1, 151-170.

4. Lumkwana, D.; du Toit, A.; Kinnear, C.; Loos, B. Autophagic flux control in neurodegeneration: Progress and precision targeting-Where do we stand? Progress in Neurobiology 2017, 153, 64-85, doi:https://doi.org/10.1016/j.pneurobio.2017.03.006.

5. Marsh, A.P. Molecular mechanisms of proteinopathies across neurodegenerative disease: a review. Neurological Research and Practice 2019, 1, 35, doi:10.1186/s42466-019-0039-8.

6. Boland, B.; Yu, W.H.; Corti, O.; Mollereau, B.; Henriques, A.; Bezard, E.; Pastores, G.M.; Rubinsztein, D.C.; Nixon, R.A.; Duchen, M.R., et al. Promoting the clearance of neurotoxic proteins in neurodegenerative disorders of ageing. Nature reviews. Drug discovery 2018, 17, 660-688, doi:10.1038/nrd.2018.109.

7. Golde, T.E.; Borchelt, D.R.; Giasson, B.I.; Lewis, J. Thinking laterally about neurodegenerative proteinopathies. The Journal of clinical investigation 2013, 123, 1847-1855, doi:10.1172/jci66029.

8. Martínez, G.; Duran-Aniotz, C.; Cabral-Miranda, F.; Vivar, J.P.; Hetz, C. Endoplasmic reticulum proteostasis impairment in aging. Aging cell 2017, 16, 615-623, doi:10.1111/acel.12599.

9. López-Otín, C.; Blasco, M.A.; Partridge, L.; Serrano, M.; Kroemer, G. The hallmarks of aging. Cell 2013, 153, 1194-1217, doi:10.1016/j.cell.2013.05.039.

10. Labbadia, J.; Morimoto, R.I. The biology of proteostasis in aging and disease. Annual review of biochemistry 2015, 84, 435-464.

11. Morimoto, R.I.; Cuervo, A.M. Proteostasis and the aging proteome in health and disease. The journals of gerontology. Series A, Biological sciences and medical sciences 2014, 69 Suppl 1, S33-38, doi:10.1093/gerona/glu049.

12. Morano, K.A.; Grant, C.M.; Moye-Rowley, W.S. The response to heat shock and oxidative stress in Saccharomyces cerevisiae. Genetics 2012, 190, 1157-1195, doi:10.1534/genetics.111.128033.

13. Ravishankar, B.; Liu, H.; Shinde, R.; Chaudhary, K.; Xiao, W.; Bradley, J.; Koritzinsky, M.; Madaio, M.P.; McGaha, T.L. The amino acid sensor GCN2 inhibits inflammatory responses to apoptotic cells promoting tolerance and suppressing systemic autoimmunity. Proc Natl Acad Sci U S A 2015, 112, 10774-10779, doi:10.1073/pnas.1504276112.

14. Ferrington, D.A.; Gregerson, D.S. Immunoproteasomes: structure, function, and antigen presentation. Prog Mol Biol Transl Sci 2012, 109, 75-112, doi:10.1016/B978-0-12-397863-9.00003-1.

15. Luo, H.; Chiang, H.-H.; Louw, M.; Susanto, A.; Chen, D. Nutrient Sensing and the Oxidative Stress Response. Trends Endocrinol Metab 2017, 28, 449-460, doi:10.1016/j.tem.2017.02.008.

16. Reichmann, D.; Voth, W.; Jakob, U. Maintaining a Healthy Proteome during Oxidative Stress. Molecular cell 2018, 69, 203-213, doi:10.1016/j.molcel.2017.12.021.

17. Powers, E.T.; Morimoto, R.I.; Dillin, A.; Kelly, J.W.; Balch, W.E. Biological and chemical approaches to diseases of proteostasis deficiency. Annual review of biochemistry 2009, 78, 959-991, doi:10.1146/annurev.biochem.052308.114844.

18. Korovila, I.; Hugo, M.; Castro, J.P.; Weber, D.; Höhn, A.; Grune, T.; Jung, T. Proteostasis, oxidative stress and aging. Redox biology 2017, 13, 550-567, doi:10.1016/j.redox.2017.07.008.

19. Lipina, C.; Hundal, H.S. Modulation of cellular redox homeostasis by the endocannabinoid system. Open Biol 2016, 6, 150276-150276, doi:10.1098/rsob.150276. 
20. Ambrożewicz, E.; Wójcik, P.; Wroński, A.; Łuczaj, W.; Jastrząb, A.; Žarković, N.; Skrzydlewska, E. Pathophysiological Alterations of Redox Signaling and Endocannabinoid System in Granulocytes and Plasma of Psoriatic Patients. Cells 2018, 7, 159, doi:10.3390/cells7100159.

21. Gomes, B.A.Q.; Silva, J.P.B.; Romeiro, C.F.R.; Dos Santos, S.M.; Rodrigues, C.A.; Gonçalves, P.R.; Sakai, J.T.; Mendes, P.F.S.; Varela, E.L.P.; Monteiro, M.C. Neuroprotective mechanisms of resveratrol in Alzheimer's disease: role of SIRT1. Oxidative medicine and cellular longevity 2018, 2018.

22. Llanos-González, E.; Henares-Chavarino, Á.A.; Pedrero-Prieto, C.M.; García-Carpintero, S.; FrontiñánRubio, J.; Sancho-Bielsa, F.J.; Alcain, F.J.; Peinado, J.R.; Rabanal-Ruíz, Y.; Durán-Prado, M. Interplay between mitochondrial oxidative disorders and proteostasis in Alzheimer's disease. Frontiers in Neuroscience 2020, 13, 1444.

23. Paloczi, J.; Varga, Z.V.; Hasko, G.; Pacher, P. Neuroprotection in Oxidative Stress-Related Neurodegenerative Diseases: Role of Endocannabinoid System Modulation. Antioxidants \& redox signaling 2018, 29, 75-108, doi:10.1089/ars.2017.7144.

24. Linge, R.; Jimenez-Sanchez, L.; Campa, L.; Pilar-Cuellar, F.; Vidal, R.; Pazos, A.; Adell, A.; Diaz, A. Cannabidiol induces rapid-acting antidepressant-like effects and enhances cortical 5-HT/glutamate neurotransmission: role of 5-HT1A receptors. Neuropharmacology 2016, 103, 16-26.

25. Grlie, L. A comparative study on some chemical and biological characteristics of various samples of cannabis resin. Bull Narcot 1976, 14, 37-46.

26. Pacher, P.; Bátkai, S.; Kunos, G. The endocannabinoid system as an emerging target of pharmacotherapy. Pharmacological reviews 2006, 58, 389-462.

27. Andre, C.M.; Hausman, J.-F.; Guerriero, G. Cannabis sativa: the plant of the thousand and one molecules. Frontiers in plant science 2016, 7, 19.

28. Giacoppo, S.; Mazzon, E. Can cannabinoids be a potential therapeutic tool in amyotrophic lateral sclerosis? Neural Regen Res 2016, 11, 1896-1899.

29. Huestis, M.A.; Solimini, R.; Pichini, S.; Pacifici, R.; Carlier, J.; Busardo, F.P. Cannabidiol Adverse Effects and Toxicity. Current neuropharmacology 2019, 17, 974-989, doi:10.2174/1570159x17666190603171901.

30. Campos, A.C.; Fogaça, M.V.; Sonego, A.B.; Guimarães, F.S. Cannabidiol, neuroprotection and neuropsychiatric disorders. Pharmacological research 2016, 112, 119-127.

31. Iuvone, T.; Esposito, G.; De Filippis, D.; Scuderi, C.; Steardo, L. Cannabidiol: a promising drug for neurodegenerative disorders? CNS neuroscience E therapeutics 2009, 15, 65-75.

32. HAMPSON, A.J.; GRIMALDI, M.; LOLIC, M.; WINK, D.; ROSENTHAL, R.; AXELROD, J. Neuroprotective Antioxidants from Marijuanaa. Annals of the New York Academy of Sciences 2000, 899, 274-282, doi:10.1111/j.1749-6632.2000.tb06193.x.

33. Fernandez-Ruiz, J.; Sagredo, O.; Pazos, M.R.; Garcia, C.; Pertwee, R.; Mechoulam, R.; Martinez-Orgado, J. Cannabidiol for neurodegenerative disorders: important new clinical applications for this phytocannabinoid? British journal of clinical pharmacology 2013, 75, 323-333, doi:10.1111/j.13652125.2012.04341.x.

34. Mechoulam, R.; Shani, A.; Edery, H.; Grunfeld, Y. Chemical basis of hashish activity. Science 1970, 169, 611612, doi:10.1126/science.169.3945.611.

35. Bonini, S.A.; Premoli, M.; Tambaro, S.; Kumar, A.; Maccarinelli, G.; Memo, M.; Mastinu, A. Cannabis sativa: A comprehensive ethnopharmacological review of a medicinal plant with a long history. Journal of ethnopharmacology 2018, 227, 300-315, doi:10.1016/j.jep.2018.09.004.

36. Hanus, L.O.; Meyer, S.M.; Munoz, E.; Taglialatela-Scafati, O.; Appendino, G. Phytocannabinoids: a unified critical inventory. Natural product reports 2016, 33, 1357-1392, doi:10.1039/c6np00074f.

37. Mechoulam, R.; Peters, M.; Murillo-Rodriguez, E.; Hanus, L.O. Cannabidiol--recent advances. Chemistry $\mathcal{E}$ biodiversity 2007, 4, 1678-1692, doi:10.1002/cbdv.200790147.

38. Campos, A.C.; Moreira, F.A.; Gomes, F.V.; Del Bel, E.A.; Guimaraes, F.S. Multiple mechanisms involved in the large-spectrum therapeutic potential of cannabidiol in psychiatric disorders. Philosophical Transactions of the Royal Society B: Biological Sciences 2012, 367, 3364-3378.

39. Mecha, M.; Feliu, A.; Inigo, P.M.; Mestre, L.; Carrillo-Salinas, F.J.; Guaza, C. Cannabidiol provides longlasting protection against the deleterious effects of inflammation in a viral model of multiple sclerosis: a role for A2A receptors. Neurobiology of disease 2013, 59, 141-150.

40. Esposito, G.; Scuderi, C.; Valenza, M.; Togna, G.I.; Latina, V.; De Filippis, D.; Cipriano, M.; Carratu, M.R.; Iuvone, T.; Steardo, L. Cannabidiol reduces Abeta-induced neuroinflammation and promotes hippocampal 
neurogenesis through PPARgamma involvement. Plos one 2011, 6, e28668, doi:10.1371/journal.pone.0028668.

41. Napimoga, M.H.; Benatti, B.B.; Lima, F.O.; Alves, P.M.; Campos, A.C.; Pena-Dos-Santos, D.R.; Severino, F.P.; Cunha, F.Q.; Guimaraes, F.S. Cannabidiol decreases bone resorption by inhibiting RANK/RANKL expression and pro-inflammatory cytokines during experimental periodontitis in rats. Int Immunopharmacol 2009, 9, 216-222, doi:10.1016/j.intimp.2008.11.010.

42. Campos, A.; Brant, F.; Miranda, A.; Machado, F.; Teixeira, A. Cannabidiol increases survival and promotes rescue of cognitive function in a murine model of cerebral malaria. Neuroscience 2015, 289, 166-180.

43. Patel, R.; Baker, S.S.; Liu, W.; Desai, S.; Alkhouri, R.; Kozielski, R.; Mastrandrea, L.; Sarfraz, A.; Cai, W.; Vlassara, H. Effect of dietary advanced glycation end products on mouse liver. PloS one 2012, 7.

44. Schiavon, A.P.; Soares, L.M.; Bonato, J.M.; Milani, H.; Guimaraes, F.S.; de Oliveira, R.M.W. Protective effects of cannabidiol against hippocampal cell death and cognitive impairment induced by bilateral common carotid artery occlusion in mice. Neurotoxicity research 2014, 26, 307-316.

45. Perez, M.; Benitez, S.U.; Cartarozzi, L.P.; Del Bel, E.; Guimaraes, F.S.; Oliveira, A.L. Neuroprotection and reduction of glial reaction by cannabidiol treatment after sciatic nerve transection in neonatal rats. European Journal of Neuroscience 2013, 38, 3424-3434.

46. Kozela, E.; Pietr, M.; Juknat, A.; Rimmerman, N.; Levy, R.; Vogel, Z. Cannabinoids Delta(9)tetrahydrocannabinol and cannabidiol differentially inhibit the lipopolysaccharide-activated NF-kappaB and interferon-beta/STAT proinflammatory pathways in BV-2 microglial cells. J Biol Chem 2010, 285, 16161626, doi:10.1074/jbc.M109.069294.

47. Morgan, C.J.; Schafer, G.; Freeman, T.P.; Curran, H.V. Impact of cannabidiol on the acute memory and psychotomimetic effects of smoked cannabis: naturalistic study: naturalistic study [corrected]. The British journal of psychiatry : the journal of mental science 2010, 197, 285-290, doi:10.1192/bjp.bp.110.077503.

48. Morgan, C.J.; Curran, H.V. Effects of cannabidiol on schizophrenia-like symptoms in people who use cannabis. The British journal of psychiatry : the journal of mental science 2008, 192, 306-307, doi:10.1192/bjp.bp.107.046649.

49. D'Souza, D.C.; Perry, E.; MacDougall, L.; Ammerman, Y.; Cooper, T.; Wu, Y.T.; Braley, G.; Gueorguieva, R.; Krystal, J.H. The psychotomimetic effects of intravenous delta-9-tetrahydrocannabinol in healthy individuals: implications for psychosis. Neuropsychopharmacology : official publication of the American College of Neuropsychopharmacology 2004, 29, 1558-1572, doi:10.1038/sj.npp.1300496.

50. Scuderi, C.; Filippis, D.D.; Iuvone, T.; Blasio, A.; Steardo, A.; Esposito, G. Cannabidiol in medicine: a review of its therapeutic potential in CNS disorders. Phytotherapy research : PTR 2009, 23, 597-602, doi:10.1002/ptr.2625.

51. Grotenhermen, F. Pharmacokinetics and pharmacodynamics of cannabinoids. Clinical pharmacokinetics 2003, 42, 327-360, doi:10.2165/00003088-200342040-00003.

52. Devinsky, O.; Cilio, M.R.; Cross, H.; Fernandez-Ruiz, J.; French, J.; Hill, C.; Katz, R.; Di Marzo, V.; JutrasAswad, D.; Notcutt, W.G., et al. Cannabidiol: pharmacology and potential therapeutic role in epilepsy and other neuropsychiatric disorders. Epilepsia 2014, 55, 791-802, doi:10.1111/epi.12631.

53. Koo, C.M.; Kang, H.C. Could Cannabidiol be a Treatment Option for Intractable Childhood and Adolescent Epilepsy? Journal of epilepsy research 2017, 7, 16-20, doi:10.14581/jer.17003.

54. Corrigan, D. The pharmacology of cannabis: issues for understanding its use. EMCDDA MONOGRAPHS 2008, 30 .

55. Welty, T.E.; Luebke, A.; Gidal, B.E. Cannabidiol: promise and pitfalls. Epilepsy currents 2014, 14, 250-252, doi:10.5698/1535-7597-14.5.250.

56. Bergamaschi, M.M.; Queiroz, R.H.; Zuardi, A.W.; Crippa, J.A. Safety and side effects of cannabidiol, a Cannabis sativa constituent. Current drug safety 2011, 6, 237-249, doi:10.2174/157488611798280924.

57. Wu, H.Y.; Chu, R.M.; Wang, C.C.; Lee, C.Y.; Lin, S.H.; Jan, T.R. Cannabidiol-induced apoptosis in primary lymphocytes is associated with oxidative stress-dependent activation of caspase-8. Toxicology and applied pharmacology 2008, 226, 260-270, doi:10.1016/j.taap.2007.09.012.

58. Rosenkrantz, H.; Fleischman, R.W.; Grant, R.J. Toxicity of short-term administration of cannabinoids to rhesus monkeys. Toxicology and applied pharmacology 1981, 58, 118-131, doi:10.1016/0041-008x(81)90122-8.

59. Golde, T.E.; Miller, V.M. Proteinopathy-induced neuronal senescence: a hypothesis for brain failure in Alzheimer's and other neurodegenerative diseases. Alzheimer's research $\mathcal{E}$ therapy 2009, 1, 5, doi:10.1186/alzrt5. 
60. Uversky, V.N. Intrinsic disorder in proteins associated with neurodegenerative diseases. Frontiers in bioscience (Landmark edition) 2009, 14, 5188-5238, doi:10.2741/3594.

61. Dickson, D.W.; Huisingh, D.; Sasser, J.N. Dehydrogenases, Acid and Alkaline Phosphatases, and Esterases for Chemotaxonomy of Selected Meloidogyne, Ditylenchus, Heterodera and Aphelenchus spp. Journal of nematology 1971, 3, 1-16.

62. Gandhi, J.; Antonelli, A.C.; Afridi, A.; Vatsia, S.; Joshi, G.; Romanov, V.; Murray, I.V.J.; Khan, S.A. Protein misfolding and aggregation in neurodegenerative diseases: a review of pathogeneses, novel detection strategies, and potential therapeutics. Reviews in the neurosciences 2019, 30, 339-358, doi:10.1515/revneuro2016-0035.

63. Vanni, S.; Colini Baldeschi, A.; Zattoni, M.; Legname, G. Brain aging: A Ianus-faced player between health and neurodegeneration. J Neurosci Res 2020, 98, 299-311, doi:10.1002/jnr.24379.

64. dos Santos, T. Protein Misfolding and Propagation in Neurodegenerative Diseases. Young Perspectives for Old Diseases. Bentham Science Publishers: 2015.

65. Gu, Z.; Nakamura, T.; Lipton, S.A. Redox reactions induced by nitrosative stress mediate protein misfolding and mitochondrial dysfunction in neurodegenerative diseases. Molecular neurobiology 2010, 41, 55-72, doi:10.1007/s12035-010-8113-9.

66. Solomon, I.H.; Biasini, E.; Harris, D.A. Ion channels induced by the prion protein: mediators of neurotoxicity. Prion 2012, 6, 40-45, doi:10.4161/pri.6.1.18627.

67. Melo, A.; Monteiro, L.; Lima, R.M.; de Oliveira, D.M.; de Cerqueira, M.D.; El-Bachá, R.S. Oxidative stress in neurodegenerative diseases: mechanisms and therapeutic perspectives. Oxidative medicine and cellular longevity 2011, 2011.

68. Pisoschi, A.M.; Pop, A. The role of antioxidants in the chemistry of oxidative stress: A review. European journal of medicinal chemistry 2015, 97, 55-74, doi:10.1016/j.ejmech.2015.04.040.

69. Niedzielska, E.; Smaga, I.; Gawlik, M.; Moniczewski, A.; Stankowicz, P.; Pera, J.; Filip, M. Oxidative Stress in Neurodegenerative Diseases. Molecular neurobiology 2016, 53, 4094-4125, doi:10.1007/s12035-015-9337-5.

70. Chen, X.; Guo, C.; Kong, J. Oxidative stress in neurodegenerative diseases. Neural Regen Res 2012, 7, 376385.

71. Kim, G.H.; Kim, J.E.; Rhie, S.J.; Yoon, S. The Role of Oxidative Stress in Neurodegenerative Diseases. Experimental neurobiology 2015, 24, 325-340, doi:10.5607/en.2015.24.4.325.

72. Salazar, M.; Carracedo, A.; Salanueva, I.J.; Hernández-Tiedra, S.; Lorente, M.; Egia, A.; Vázquez, P.; Blázquez, C.; Torres, S.; García, S., et al. Cannabinoid action induces autophagy-mediated cell death through stimulation of ER stress in human glioma cells. The Journal of clinical investigation 2009, 119, 13591372, doi:10.1172/jci37948.

73. Hampson, A.J.; Grimaldi, M.; Axelrod, J.; Wink, D. Cannabidiol and (-)Delta9-tetrahydrocannabinol are neuroprotective antioxidants. Proc Natl Acad Sci U S A 1998, 95, 8268-8273, doi:10.1073/pnas.95.14.8268.

74. Esposito, G.; De Filippis, D.; Carnuccio, R.; Izzo, A.A.; Iuvone, T. The marijuana component cannabidiol inhibits beta-amyloid-induced tau protein hyperphosphorylation through Wnt/beta-catenin pathway rescue in PC12 cells. Journal of molecular medicine (Berlin, Germany) 2006, 84, 253-258, doi:10.1007/s00109-0050025-1.

75. Iuvone, T.; Esposito, G.; Esposito, R.; Santamaria, R.; Di Rosa, M.; Izzo, A.A. Neuroprotective effect of cannabidiol, a non-psychoactive component from Cannabis sativa, on beta-amyloid-induced toxicity in PC12 cells. Journal of neurochemistry 2004, 89, 134-141, doi:10.1111/j.1471-4159.2003.02327.x.

76. Mecha, M.; Torrao, A.S.; Mestre, L.; Carrillo-Salinas, F.J.; Mechoulam, R.; Guaza, C. Cannabidiol protects oligodendrocyte progenitor cells from inflammation-induced apoptosis by attenuating endoplasmic reticulum stress. Cell Death Dis 2012, 3, e331, doi:10.1038/cddis.2012.71.

77. Lupica, C.R.; Hu, Y.; Devinsky, O.; Hoffman, A.F. Cannabinoids as hippocampal network administrators. Neuropharmacology 2017, 124, 25-37, doi:10.1016/j.neuropharm.2017.04.003.

78. Ricart, K.C.; Fiszman, M.L. Hydrogen peroxide-induced neurotoxicity in cultured cortical cells grown in serum-free and serum-containing media. Neurochemical research 2001, 26, 801-808, doi:10.1023/a:1011660001941.

79. Juknat, A.; Pietr, M.; Kozela, E.; Rimmerman, N.; Levy, R.; Coppola, G.; Geschwind, D.; Vogel, Z. Differential transcriptional profiles mediated by exposure to the cannabinoids cannabidiol and $\Delta 9$ tetrahydrocannabinol in BV-2 microglial cells. British journal of pharmacology 2012, 165, 2512-2528. 
80. Jastrząb, A.; Gęgotek, A.; Skrzydlewska, E. Cannabidiol Regulates the Expression of Keratinocyte Proteins Involved in the Inflammation Process through Transcriptional Regulation. Cells 2019, 8, doi:10.3390/cells8080827.

81. Casares, L.; García, V.; Garrido-Rodríguez, M.; Millán, E.; Collado, J.A.; García-Martín, A.; Peñarando, J.; Calzado, M.A.; de la Vega, L.; Muñoz, E. Cannabidiol induces antioxidant pathways in keratinocytes by targeting BACH1. Redox Biology 2020, 28, 101321, doi:https://doi.org/10.1016/j.redox.2019.101321.

82. Gozzelino, R.; Jeney, V.; Soares, M.P. Mechanisms of cell protection by heme oxygenase-1. Annual review of pharmacology and toxicology 2010, 50, 323-354, doi:10.1146/annurev.pharmtox.010909.105600.

83. Milatovic, D.; Zaja-Milatovic, S.; Breyer, R.M.; Aschner, M.; Montine, T.J. Neuroinflammation and oxidative injury in developmental neurotoxicity. In Reproductive and Developmental Toxicology, Elsevier: 2017; pp. 1051-1061.

84. Branca, J.J.V.; Morucci, G.; Becatti, M.; Carrino, D.; Ghelardini, C.; Gulisano, M.; Di Cesare Mannelli, L.; Pacini, A. Cannabidiol Protects Dopaminergic Neuronal Cells from Cadmium. Int J Environ Res Public Health 2019, 16, doi:10.3390/ijerph16224420.

85. Solleiro-Villavicencio, H.; Rivas-Arancibia, S. Effect of chronic oxidative stress on neuroinflammatory response mediated by CD4+ T cells in neurodegenerative diseases. Frontiers in cellular neuroscience 2018, 12, 114.

86. Dos-Santos-Pereira, M.; Guimaraes, F.S.; Del-Bel, E.; Raisman-Vozari, R.; Michel, P.P. Cannabidiol prevents LPS-induced microglial inflammation by inhibiting ROS/NF-kappaB-dependent signaling and glucose consumption. Glia 2020, 68, 561-573, doi:10.1002/glia.23738.

87. Oláh, A.; Tóth, B.I.; Borbíró, I.; Sugawara, K.; Szöllõsi, A.G.; Czifra, G.; Pál, B.; Ambrus, L.; Kloepper, J.; Camera, E. Cannabidiol exerts sebostatic and antiinflammatory effects on human sebocytes. The Journal of clinical investigation 2014, 124, 3713-3724.

88. De Ternay, J.; Naassila, M.; Nourredine, M.; Louvet, A.; Bailly, F.; Sescousse, G.; Maurage, P.; Cottencin, O.; Carrieri, P.M.; Rolland, B. Therapeutic prospects of cannabidiol for alcohol use disorder and alcoholrelated damages on the liver and the brain. Front Pharmacol 2019, 10.

89. Hartmann, A.; Lisboa, S.F.; Sonego, A.B.; Coutinho, D.; Gomes, F.V.; Guimaraes, F.S. Cannabidiol attenuates aggressive behavior induced by social isolation in mice: Involvement of 5-HT1A and CB1 receptors. Progress in Neuro-Psychopharmacology and Biological Psychiatry 2019, 94, 109637.

90. Karunaweera, N.; Raju, R.; Gyengesi, E.; Münch, G. Plant polyphenols as inhibitors of NF- $\kappa$ B induced cytokine production-a potential anti-inflammatory treatment for Alzheimer's disease? Frontiers in molecular neuroscience 2015, 8, 24.

91. Mattson, M.P.; Camandola, S. NF- $\kappa B$ in neuronal plasticity and neurodegenerative disorders. The Journal of clinical investigation 2001, 107, 247-254.

92. Necela, B.M.; Su, W.; Thompson, E.A. Toll-like receptor 4 mediates cross-talk between peroxisome proliferator-activated receptor $\gamma$ and nuclear factor- $\kappa$ B in macrophages. Immunology 2008, 125, 344-358.

93. Giacoppo, S.; Galuppo, M.; Montaut, S.; Iori, R.; Rollin, P.; Bramanti, P.; Mazzon, E. An overview on neuroprotective effects of isothiocyanates for the treatment of neurodegenerative diseases. Fitoterapia 2015, 106, 12-21.

94. Rajan, T.S.; De Nicola, G.R.; Iori, R.; Rollin, P.; Bramanti, P.; Mazzon, E. Anticancer activity of glucomoringin isothiocyanate in human malignant astrocytoma cells. Fitoterapia 2016, 110, 1-7.

95. Cabral, G.A.; Griffin-Thomas, L. Emerging role of the cannabinoid receptor CB 2 in immune regulation: therapeutic prospects for neuroinflammation. Expert reviews in molecular medicine 2009, 11.

96. Al-Ghezi, Z.Z.; Busbee, P.B.; Alghetaa, H.; Nagarkatti, P.S.; Nagarkatti, M. Combination of cannabinoids, delta-9-tetrahydrocannabinol (THC) and cannabidiol (CBD), mitigates experimental autoimmune encephalomyelitis (EAE) by altering the gut microbiome. Brain, behavior, and immunity 2019, 82, 25-35.

97. Peres, F.F.; Lima, A.C.; Hallak, J.E.; Crippa, J.A.; Silva, R.H.; Abílio, V.C. Cannabidiol as a promising strategy to treat and prevent movement disorders? Front Pharmacol 2018, 9, 482.

98. O'Sullivan, S.E.; Sun, Y.; Bennett, A.J.; Randall, M.D.; Kendall, D.A. Time-dependent vascular actions of cannabidiol in the rat aorta. Eur J Pharmacol 2009, 612, 61-68, doi:10.1016/j.ejphar.2009.03.010.

99. Gloire, G.; Legrand-Poels, S.; Piette, J. NF- $\kappa$ B activation by reactive oxygen species: fifteen years later. Biochemical pharmacology 2006, 72, 1493-1505.

100. Lee, W.-S.; Erdelyi, K.; Matyas, C.; Mukhopadhyay, P.; Varga, Z.V.; Liaudet, L.; Haskó, G.; Čiháková, D.; Mechoulam, R.; Pacher, P. Cannabidiol limits T cell-mediated chronic autoimmune myocarditis: implications to autoimmune disorders and organ transplantation. Molecular Medicine 2016, 22, 136-146. 
101. Ruiz-Valdepeñas, L.; Martínez-Orgado, J.A.; Benito, C.; Millán, Á.; Tolón, R.M.; Romero, J. Cannabidiol reduces lipopolysaccharide-induced vascular changes and inflammation in the mouse brain: an intravital microscopy study. Journal of neuroinflammation 2011, 8, 5 .

102. Kozela, E.; Juknat, A.; Kaushansky, N.; Ben-Nun, A.; Coppola, G.; Vogel, Z. Cannabidiol, a nonpsychoactive cannabinoid, leads to EGR2-dependent anergy in activated encephalitogenic T cells. Journal of neuroinflammation 2015, 12, 52.

103. Esposito, G.; De Filippis, D.; Maiuri, M.C.; De Stefano, D.; Carnuccio, R.; Iuvone, T. Cannabidiol inhibits inducible nitric oxide synthase protein expression and nitric oxide production in $\beta$-amyloid stimulated PC12 neurons through p38 MAP kinase and NF- $\kappa$ B involvement. Neuroscience letters 2006, 399, 91-95.

104. Travaglia, A.; La Mendola, D. Zinc Interactions With Brain-Derived Neurotrophic Factor and Related Peptide Fragments. In Vitamins and hormones, Elsevier: 2017; Vol. 104, pp. 29-56.

105. Barichello, T.; Ceretta, R.A.; Generoso, J.S.; Moreira, A.P.; Simões, L.R.; Comim, C.M.; Quevedo, J.; Vilela, M.C.; Zuardi, A.W.; Crippa, J.A. Cannabidiol reduces host immune response and prevents cognitive impairments in Wistar rats submitted to pneumococcal meningitis. European journal of pharmacology 2012, 697, 158-164.

106. Valvassori, S.S.; Elias, G.; de Souza, B.; Petronilho, F.; Dal-Pizzol, F.; Kapczinski, F.; Trzesniak, C.; Tumas, V.; Dursun, S.; Nisihara Chagas, M.H. Effects of cannabidiol on amphetamine-induced oxidative stress generation in an animal model of mania. Journal of Psychopharmacology 2011, 25, 274-280.

107. Moreno-Martet, M.; Feliú, A.; Espejo-Porras, F.; Mecha, M.; Carrillo-Salinas, F.J.; Fernández-Ruiz, J.; Guaza, C.; de Lago, E. The disease-modifying effects of a Sativex-like combination of phytocannabinoids in mice with experimental autoimmune encephalomyelitis are preferentially due to $\Delta 9$-tetrahydrocannabinol acting through CB1 receptors. Multiple sclerosis and related disorders 2015, 4, 505-511.

108. Feliú, A.; Moreno-Martet, M.; Mecha, M.; Carrillo-Salinas, F.; De Lago, E.; Fernández-Ruiz, J.; Guaza, C. AS ativex®-like combination of phytocannabinoids as a disease-modifying therapy in a viral model of multiple sclerosis. British journal of pharmacology 2015, 172, 3579-3595.

109. Al-Ghezi, Z.Z.; Miranda, K.; Nagarkatti, M.; Nagarkatti, P.S. Combination of cannabinoids, $\Delta 9$ tetrahydrocannabinol and cannabidiol, ameliorates experimental multiple sclerosis by suppressing neuroinflammation through regulation of miRNA-mediated signaling pathways. Frontiers in immunology 2019, 10, 1921.

110. De Petrocellis, L.; Nabissi, M.; Santoni, G.; Ligresti, A. Chapter Eight - Actions and Regulation of Ionotropic Cannabinoid Receptors. In Advances in Pharmacology, Kendall, D., Alexander, S.P.H., Eds. Academic Press: 2017; Vol. 80, pp. 249-289.

111. Ghovanloo, M.R.; Shuart, N.G.; Mezeyova, J.; Dean, R.A.; Ruben, P.C.; Goodchild, S.J. Inhibitory effects of cannabidiol on voltage-dependent sodium currents. J Biol Chem 2018, 293, 16546-16558, doi:10.1074/jbc.RA118.004929.

112. Giacoppo, S.; Galuppo, M.; Pollastro, F.; Grassi, G.; Bramanti, P.; Mazzon, E. A new formulation of cannabidiol in cream shows therapeutic effects in a mouse model of experimental autoimmune encephalomyelitis. DARU Journal of Pharmaceutical Sciences 2015, 23, 48, doi:10.1186/s40199-015-0131-8.

113. Wang, Y.; Mukhopadhyay, P.; Cao, Z.; Wang, H.; Feng, D.; Haskó, G.; Mechoulam, R.; Gao, B.; Pacher, P. Cannabidiol attenuates alcohol-induced liver steatosis, metabolic dysregulation, inflammation and neutrophil-mediated injury. Sci Rep 2017, 7, 12064, doi:10.1038/s41598-017-10924-8.

114. Atalay, S.; Jarocka-Karpowicz, I.; Skrzydlewska, E. Antioxidative and Anti-Inflammatory Properties of Cannabidiol. Antioxidants 2020, 9, 21.

115. Green, D.E.; Kang, B.Y.; Murphy, T.C.; Hart, C.M. Peroxisome proliferator-activated receptor gamma (PPAR $\gamma$ ) regulates thrombospondin-1 and Nox4 expression in hypoxia-induced human pulmonary artery smooth muscle cell proliferation. Pulmonary circulation 2012, 2, 483-491, doi:10.4103/2045-8932.105037.

116. Grzybowska, E.A. Calcium-binding proteins with disordered structure and their role in secretion, storage, and cellular signaling. Biomolecules 2018, 8, 42.

117. Lee, B.H.; Lee, M.J.; Park, S.; Oh, D.C.; Elsasser, S.; Chen, P.C.; Gartner, C.; Dimova, N.; Hanna, J.; Gygi, S.P., et al. Enhancement of proteasome activity by a small-molecule inhibitor of USP14. Nature 2010, 467, 179-184, doi:10.1038/nature09299.

118. Seifert, U.; Bialy, L.P.; Ebstein, F.; Bech-Otschir, D.; Voigt, A.; Schröter, F.; Prozorovski, T.; Lange, N.; Steffen, J.; Rieger, M., et al. Immunoproteasomes preserve protein homeostasis upon interferon-induced oxidative stress. Cell 2010, 142, 613-624, doi:10.1016/j.cell.2010.07.036. 
119. Jung, T.; Catalgol, B.; Grune, T. The proteasomal system. Molecular aspects of medicine 2009, 30, 191-296, doi:10.1016/j.mam.2009.04.001.

120. Ciechanover, A.; Brundin, P. The ubiquitin proteasome system in neurodegenerative diseases: sometimes the chicken, sometimes the egg. Neuron 2003, 40, 427-446, doi:10.1016/s0896-6273(03)00606-8.

121. Dahlmann, B. Role of proteasomes in disease. BMC biochemistry 2007, 8 Suppl 1, S3, doi:10.1186/1471-20918-s1-s3.

122. Andreasen, M.; Lorenzen, N.; Otzen, D. Interactions between misfolded protein oligomers and membranes: A central topic in neurodegenerative diseases? Biochimica et Biophysica Acta (BBA) - Biomembranes 2015, 1848, 1897-1907, doi:https://doi.org/10.1016/j.bbamem.2015.01.018.

123. Di Scala, C.; Yahi, N.; Boutemeur, S.; Flores, A.; Rodriguez, L.; Chahinian, H.; Fantini, J. Common molecular mechanism of amyloid pore formation by Alzheimer's $\beta$-amyloid peptide and $\alpha$-synuclein. Scientific Reports 2016, 6, 28781, doi:10.1038/srep28781.

124. Shrivastava, A.N.; Aperia, A.; Melki, R.; Triller, A. Physico-pathologic mechanisms involved in neurodegeneration: misfolded protein-plasma membrane interactions. Neuron 2017, 95, 33-50.

125. Soto, C. Unfolding the role of protein misfolding in neurodegenerative diseases. Nature Reviews Neuroscience 2003, 4, 49-60.

126. Zhang, Y.; Li, P.; Feng, J.; Wu, M. Dysfunction of NMDA receptors in Alzheimer's disease. Neurological Sciences 2016, 37, 1039-1047.

127. Carvajal, F.J.; Mattison, H.A.; Cerpa, W. Role of NMDA receptor-mediated glutamatergic signaling in chronic and acute neuropathologies. Neural plasticity 2016, 2016.

128. Leist, M.; Volbracht, C.; Kühnle, S.; Fava, E.; Ferrando-May, E.; Nicotera, P. Caspase-mediated apoptosis in neuronal excitotoxicity triggered by nitric oxide. Molecular Medicine 1997, 3, 750-764.

129. Tenneti, L.; D'Emilia, D.M.; Troy, C.M.; Lipton, S.A. Role of caspases in N-methyl-D-aspartate-induced apoptosis in cerebrocortical neurons. Journal of neurochemistry 1998, 71, 946-959.

130. Jones, N.A.; Hill, A.J.; Smith, I.; Bevan, S.A.; Williams, C.M.; Whalley, B.J.; Stephens, G.J. Cannabidiol displays antiepileptiform and antiseizure properties in vitro and in vivo. Journal of Pharmacology and Experimental Therapeutics 2010, 332, 569-577.

131. Consroe, P.; Benedito, M.A.; Leite, J.R.; Carlini, E.A.; Mechoulam, R. Effects of cannabidiol on behavioral seizures caused by convulsant drugs or current in mice. European journal of pharmacology 1982, 83, 293-298.

132. Wallace, M.J.; Wiley, J.L.; Martin, B.R.; DeLorenzo, R.J. Assessment of the role of CB1 receptors in cannabinoid anticonvulsant effects. European journal of pharmacology 2001, 428, 51-57.

133. El-Remessy, A.B.; Khalil, I.E.; Matragoon, S.; Abou-Mohamed, G.; Tsai, N.-J.; Roon, P.; Caldwell, R.B.; Caldwell, R.W.; Green, K.; Liou, G.I. Neuroprotective effect of $(-) \Delta$ 9-tetrahydrocannabinol and cannabidiol in N-methyl-D-aspartate-induced retinal neurotoxicity: involvement of peroxynitrite. The American journal of pathology 2003, 163, 1997-2008.

134. Castillo, A.; Tolón, M.R.; Fernández-Ruiz, J.; Romero, J.; Martinez-Orgado, J. The neuroprotective effect of cannabidiol in an in vitro model of newborn hypoxic-ischemic brain damage in mice is mediated by CB2 and adenosine receptors. Neurobiology of disease 2010, 37, 434-440, doi:https://doi.org/10.1016/j.nbd.2009.10.023.

135. Gobira, P.H.; Vilela, L.R.; Gonçalves, B.D.C.; Santos, R.P.M.; de Oliveira, A.C.; Vieira, L.B.; Aguiar, D.C.; Crippa, J.A.; Moreira, F.A. Cannabidiol, a Cannabis sativa constituent, inhibits cocaine-induced seizures in mice: Possible role of the mTOR pathway and reduction in glutamate release. NeuroToxicology 2015, 50, 116121, doi:https://doi.org/10.1016/j.neuro.2015.08.007.

136. Rodríguez-Muñoz, M.; Onetti, Y.; Cortés-Montero, E.; Garzón, J.; Sánchez-Blázquez, P. Cannabidiol enhances morphine antinociception, diminishes NMDA-mediated seizures and reduces stroke damage via the sigma 1 receptor. Molecular brain 2018, 11, 1-12.

137. Kim, H.W.; Kwon, Y.B.; Roh, D.H.; Yoon, S.Y.; Han, H.J.; Kim, K.W.; Beitz, A.J.; Lee, J.H. Intrathecal treatment with $\sigma 1$ receptor antagonists reduces formalin-induced phosphorylation of NMDA receptor subunit 1 and the second phase of formalin test in mice. British journal of pharmacology 2006, 148, 490-498.

138. Diaz, J.L.; Zamanillo, D.; Corbera, J.; Baeyens, J.M.; Maldonado, R.; Pericàs, M.À.; Vela, J.M.; Torrens, A. Selective sigma-1 (sig1) receptor antagonists: emerging target for the treatment of neuropathic pain. Central Nervous System Agents in Medicinal Chemistry (Formerly Current Medicinal Chemistry-Central Nervous System Agents) 2009, 9, 172-183.

139. Romero, L.; Zamanillo, D.; Nadal, X.; Sánchez-Arroyos, R.; Rivera-Arconada, I.; Dordal, A.; Montero, A.; Muro, A.; Bura, A.; Segalés, C. Pharmacological properties of S1RA, a new sigma-1 receptor antagonist that 
inhibits neuropathic pain and activity-induced spinal sensitization. British journal of pharmacology 2012, 166, 2289-2306.

140. Rodríguez-Muñoz, M.; Cortés-Montero, E.; Pozo-Rodrigálvarez, A.; Sánchez-Blázquez, P.; Garzón-Niño, J. The ON: OFF switch, $\sigma 1 \mathrm{R}-\mathrm{HINT} 1$ protein, controls GPCR-NMDA receptor cross-regulation: implications in neurological disorders. Oncotarget 2015, 6, 35458.

141. Rodriguez-Munoz, M.; Sánchez-Blázquez, P.; Herrero-Labrador, R.; Martinez-Murillo, R.; Merlos, M.; Vela, J.M.; Garzón, J. The $\sigma 1$ receptor engages the redox-regulated HINT1 protein to bring opioid analgesia under NMDA receptor negative control. Antioxidants $\mathcal{E}$ redox signaling 2015, 22, 799-818.

142. Du, Y.; Duc, N.M.; Rasmussen, S.G.; Hilger, D.; Kubiak, X.; Wang, L.; Bohon, J.; Kim, H.R.; Wegrecki, M.; Asuru, A. Assembly of a GPCR-G protein complex. Cell 2019, 177, 1232-1242. e1211.

143. Morales, P.; Reggio, P.H. An update on non-CB1, non-CB2 cannabinoid related G-protein-coupled receptors. Cannabis and cannabinoid research 2017, 2, 265-273.

144. Demuro, A.; Mina, E.; Kayed, R.; Milton, S.C.; Parker, I.; Glabe, C.G. Calcium dysregulation and membrane disruption as a ubiquitous neurotoxic mechanism of soluble amyloid oligomers. Journal of Biological Chemistry 2005, 280, 17294-17300.

145. Fukunaga, K.; Izumi, H.; Yabuki, Y.; Shinoda, Y.; Shioda, N.; Han, F. Alzheimer's disease therapeutic candidate SAK3 is an enhancer of T-type calcium channels. Journal of Pharmacological Sciences 2019, 139, 5158, doi:https://doi.org/10.1016/j.jphs.2018.11.014.

146. Egorova, P.; Popugaeva, E.; Bezprozvanny, I. Disturbed calcium signaling in spinocerebellar ataxias and Alzheimer's disease. In Proceedings of Seminars in cell \& developmental biology; pp. 127-133.

147. Marambaud, P.; Dreses-Werringloer, U.; Vingtdeux, V.J.M.n. Calcium signaling in neurodegeneration. Molecular neurodegeneration 2009, 4, 20.

148. Schampel, A.; Kuerten, S. Danger: High Voltage-The Role of Voltage-Gated Calcium Channels in Central Nervous System Pathology. Cells 2017, 6, 43, doi:10.3390/cells6040043.

149. Ross, H.R.; Napier, I.; Connor, M. Inhibition of recombinant human T-type calcium channels by Delta9tetrahydrocannabinol and cannabidiol. J Biol Chem 2008, 283, 16124-16134, doi:10.1074/jbc.M707104200.

150. Ali, R.M.; Al Kury, L.T.; Yang, K.-H.S.; Qureshi, A.; Rajesh, M.; Galadari, S.; Shuba, Y.M.; Howarth, F.C.; $\mathrm{Oz}, \mathrm{M}$. Effects of cannabidiol on contractions and calcium signaling in rat ventricular myocytes. Cell Calcium 2015, 57, 290-299, doi:https://doi.org/10.1016/j.ceca.2015.02.001.

151. Bisogno, T.; Hanuš, L.; De Petrocellis, L.; Tchilibon, S.; Ponde, D.E.; Brandi, I.; Moriello, A.S.; Davis, J.B.; Mechoulam, R.; Di Marzo, V. Molecular targets for cannabidiol and its synthetic analogues: effect on vanilloid VR1 receptors and on the cellular uptake and enzymatic hydrolysis of anandamide. British journal of pharmacology 2001, 134, 845-852.

152. Muller, C.; Morales, P.; Reggio, P.H. Cannabinoid ligands targeting TRP channels. Frontiers in molecular neuroscience 2019, 11, 487.

153. Whalley, B.J.; Gray, R.A.; Stott, C.G.; Jones, N.A. Antiseizure properties of cannabidiol (CBD) are attenuated in the absence of transient receptor potential vanilloid 1 (TRPV1) receptors (S53. 004). Neurology: 2018; Vol. 90, p S53.004.

154. Costa, B.; Giagnoni, G.; Franke, C.; Trovato, A.E.; Colleoni, M. Vanilloid TRPV1 receptor mediates the antihyperalgesic effect of the nonpsychoactive cannabinoid, cannabidiol, in a rat model of acute inflammation. British journal of pharmacology 2004, 143, 247-250.

155. De Petrocellis, L.; Ligresti, A.; Moriello, A.S.; Allarà, M.; Bisogno, T.; Petrosino, S.; Stott, C.G.; Di Marzo, V. Effects of cannabinoids and cannabinoid-enriched Cannabis extracts on TRP channels and endocannabinoid metabolic enzymes. British journal of pharmacology 2011, 163, 1479-1494.

156. Tsuji, F.; Aono, H. Role of transient receptor potential vanilloid 1 in inflammation and autoimmune diseases. Pharmaceuticals (Basel, Switzerland) 2012, 5, 837-852, doi:10.3390/ph5080837.

157. Mathur, B.; Lovinger, D. Endocannabinoid-Dopamine Interactions in Striatal Synaptic Plasticity. Front Pharmacol 2012, 3, doi:10.3389/fphar.2012.00066.

158. Soares, T.R.; Reis, S.D.; Pinho, B.R.; Duchen, M.R.; Oliveira, J.M.A. Targeting the proteostasis network in Huntington's disease. Ageing Research Reviews 2019, 49, 92-103, doi:https://doi.org/10.1016/j.arr.2018.11.006.

159. Hipp, M.S.; Park, S.-H.; Hartl, F.U. Proteostasis impairment in protein-misfolding and-aggregation diseases. Trends in cell biology 2014, 24, 506-514.

160. Blasiak, J.; Pawlowska, E.; Szczepanska, J.; Kaarniranta, K. Interplay between Autophagy and the Ubiquitin-Proteasome System and Its Role in the Pathogenesis of Age-Related Macular Degeneration. Int J Mol Sci 2019, 20, doi:10.3390/ijms20010210. 
161. Lim, M.P.; Devi, L.A.; Rozenfeld, R. Cannabidiol causes activated hepatic stellate cell death through a mechanism of endoplasmic reticulum stress-induced apoptosis. Cell death $\mathcal{E}$ disease 2011, 2, e170-e170, doi:10.1038/cddis.2011.52.

162. Kim, J.L.; Kim, B.R.; Kim, D.Y.; Jeong, Y.A.; Jeong, S.; Na, Y.J.; Park, S.H.; Yun, H.K.; Jo, M.J.; Kim, B.G., et al. Cannabidiol Enhances the Therapeutic Effects of TRAIL by Upregulating DR5 in Colorectal Cancer. Cancers (Basel) 2019, 11, 642, doi:10.3390/cancers11050642.

163. Yamaguchi, H.; Wang, H.G. CHOP is involved in endoplasmic reticulum stress-induced apoptosis by enhancing DR5 expression in human carcinoma cells. J Biol Chem 2004, 279, 45495-45502, doi:10.1074/jbc.M406933200.

164. Jeong, S.; Yun, H.K.; Jeong, Y.A.; Jo, M.J.; Kang, S.H.; Kim, J.L.; Kim, D.Y.; Park, S.H.; Kim, B.R.; Na, Y.J., et al. Cannabidiol-induced apoptosis is mediated by activation of Noxa in human colorectal cancer cells. Cancer Letters 2019, 447, 12-23, doi:https://doi.org/10.1016/j.canlet.2019.01.011.

165. Jeong, S.; Jo, M.J.; Yun, H.K.; Kim, D.Y.; Kim, B.R.; Kim, J.L.; Park, S.H.; Na, Y.J.; Jeong, Y.A.; Kim, B.G., et al. Cannabidiol promotes apoptosis via regulation of XIAP/Smac in gastric cancer. Cell death $\mathcal{E}$ disease 2019, 10, 846, doi:10.1038/s41419-019-2001-7.

166. Tanaka, K.; Matsuda, N. Proteostasis and neurodegeneration: the roles of proteasomal degradation and autophagy. Biochimica et biophysica acta 2014, 1843, 197-204, doi:10.1016/j.bbamcr.2013.03.012.

167. Nixon, R.A. The role of autophagy in neurodegenerative disease. Nature medicine 2013, 19, 983-997, doi:10.1038/nm.3232.

168. Wong, E.; Cuervo, A.M. Integration of clearance mechanisms: the proteasome and autophagy. Cold Spring Harbor perspectives in biology 2010, 2, a006734, doi:10.1101/cshperspect.a006734.

169. Shrivastava, A.; Kuzontkoski, P.M.; Groopman, J.E.; Prasad, A. Cannabidiol induces programmed cell death in breast cancer cells by coordinating the cross-talk between apoptosis and autophagy. Molecular cancer therapeutics 2011, 10, 1161-1172, doi:10.1158/1535-7163.Mct-10-1100.

170. Yang, L.; Rozenfeld, R.; Wu, D.; Devi, L.A.; Zhang, Z.; Cederbaum, A. Cannabidiol protects liver from binge alcohol-induced steatosis by mechanisms including inhibition of oxidative stress and increase in autophagy. Free Radical Biology and Medicine 2014, 68, 260-267, doi:https://doi.org/10.1016/j.freeradbiomed.2013.12.026.

171. Giacoppo, S.; Pollastro, F.; Grassi, G.; Bramanti, P.; Mazzon, E. Target regulation of PI3K/Akt/mTOR pathway by cannabidiol in treatment of experimental multiple sclerosis. Fitoterapia 2017, 116, 77-84, doi:https://doi.org/10.1016/j.fitote.2016.11.010.

172. Hosseinzadeh, M.; Nikseresht, S.; Khodagholi, F.; Naderi, N.; Maghsoudi, N. Cannabidiol Post-Treatment Alleviates Rat Epileptic-Related Behaviors and Activates Hippocampal Cell Autophagy Pathway Along with Antioxidant Defense in Chronic Phase of Pilocarpine-Induced Seizure. Journal of Molecular Neuroscience 2016, 58, 432-440, doi:10.1007/s12031-015-0703-6.

173. Nabissi, M.; Morelli, M.B.; Amantini, C.; Liberati, S.; Santoni, M.; Ricci-Vitiani, L.; Pallini, R.; Santoni, G. Cannabidiol stimulates A ml-1a-dependent glial differentiation and inhibits glioma stem-like cells proliferation by inducing autophagy in a TRPV 2-dependent manner. International journal of cancer 2015, 137, 1855-1869.

174. Salazar, M.; Carracedo, A.; Salanueva, Í.J.; Hernández-Tiedra, S.; Lorente, M.; Egia, A.; Vázquez, P.; Blázquez, C.; Torres, S.; García, S. Cannabinoid action induces autophagy-mediated cell death through stimulation of ER stress in human glioma cells. The Journal of clinical investigation 2009, 119, 1359-1372.

175. Scott, K.A.; Dalgleish, A.G.; Liu, W.M. The combination of cannabidiol and $\Delta 9$-tetrahydrocannabinol enhances the anticancer effects of radiation in an orthotopic murine glioma model. Molecular cancer therapeutics 2014, 13, 2955-2967.

176. Koay, L.C.; Rigby, R.J.; Wright, K.L. Cannabinoid-induced autophagy regulates suppressor of cytokine signaling-3 in intestinal epithelium. American journal of physiology. Gastrointestinal and liver physiology 2014, 307, G140-148, doi:10.1152/ajpgi.00317.2013.

177. Rozenfeld, R.; Devi, L.A. Regulation of CB1 cannabinoid receptor trafficking by the adaptor protein AP-3. FASEB journal : official publication of the Federation of American Societies for Experimental Biology 2008, 22, 23112322, doi:10.1096/fj.07-102731.

178. Ichimura, Y.; Waguri, S.; Sou, Y.S.; Kageyama, S.; Hasegawa, J.; Ishimura, R.; Saito, T.; Yang, Y.; Kouno, T.; Fukutomi, T., et al. Phosphorylation of p62 activates the Keap1-Nrf2 pathway during selective autophagy. Molecular cell 2013, 51, 618-631, doi:10.1016/j.molcel.2013.08.003. 
179. Roze, E.; Bonnet, C.; Betuing, S.; Caboche, J. Huntington's disease. In Diseases of DNA Repair, Springer: 2010; pp. 45-63.

180. Kumar, A.; Kumar, V.; Singh, K.; Kumar, S.; Kim, Y.-S.; Lee, Y.-M.; Kim, J.-J. Therapeutic Advances for Huntington's Disease. Brain Sciences 2020, 10, 43.

181. Gil, J.M.; Rego, A.C. Mechanisms of neurodegeneration in Huntington's disease. European Journal of Neuroscience 2008, 27, 2803-2820.

182. Sánchez-López, F.; Tasset, I.; Agüera, E.; Feijóo, M.; Fernández-Bolaños, R.; Sánchez, F.M.; Ruiz, M.C.; Cruz, A.H.; Gascón, F.; Túnez, I. Oxidative stress and inflammation biomarkers in the blood of patients with Huntington's disease. Neurological research 2012, 34, 721-724.

183. Johnson, C.D.; Davidson, B.L. Huntington's disease: progress toward effective disease-modifying treatments and a cure. Hum Mol Genet 2010, 19, R98-R102.

184. De Yébenes, J. Phase II-clinical trial on neuroprotection with cannabinoids in Huntington's disease (SATHD). EudraCT 2010.

185. Consroe, P.; Laguna, J.; Allender, J.; Snider, S.; Stern, L.; Sandyk, R.; Kennedy, K.; Schram, K. Controlled clinical trial of cannabidiol in Huntington's disease. Pharmacology Biochemistry and Behavior 1991, 40, 701708.

186. Abdel-Salam, O. Cannabis for Basal Ganglia Disorders (Parkinson Disease and Huntington Disease). In Handbook of Cannabis and Related Pathologies, Elsevier: 2017; pp. 917-930.

187. da Silva, V.K.; de Freitas, B.S.; Garcia, R.C.L.; Monteiro, R.T.; Hallak, J.E.; Zuardi, A.W.; Crippa, J.A.S.; Schröder, N. Antiapoptotic effects of cannabidiol in an experimental model of cognitive decline induced by brain iron overload. Translational Psychiatry 2018, 8, 176, doi:10.1038/s41398-018-0232-5.

188. Morales, P.; Isawi, I.; Reggio, P.H. Towards a better understanding of the cannabinoid-related orphan receptors GPR3, GPR6, and GPR12. Drug metabolism reviews 2018, 50, 74-93, doi:10.1080/03602532.2018.1428616.

189. Hodges, A.; Strand, A.D.; Aragaki, A.K.; Kuhn, A.; Sengstag, T.; Hughes, G.; Elliston, L.A.; Hartog, C.; Goldstein, D.R.; Thu, D., et al. Regional and cellular gene expression changes in human Huntington's disease brain. Hum Mol Genet 2006, 15, 965-977, doi:10.1093/hmg/ddl013.

190. Sagredo, O.; Ramos, J.A.; Decio, A.; Mechoulam, R.; Fernandez-Ruiz, J. Cannabidiol reduced the striatal atrophy caused 3-nitropropionic acid in vivo by mechanisms independent of the activation of cannabinoid, vanilloid TRPV1 and adenosine A2A receptors. Eur J Neurosci 2007, 26, 843-851, doi:10.1111/j.14609568.2007.05717.x.

191. Sagredo, O.; Pazos, M.R.; Valdeolivas, S.; Fernandez-Ruiz, J. Cannabinoids: novel medicines for the treatment of Huntington's disease. Recent Pat CNS Drug Discov 2012, 7, 41-48, doi:10.2174/157488912798842278.

192. Valdeolivas, S.; Sagredo, O.; Delgado, M.; Pozo, M.A.; Fernández-Ruiz, J. Effects of a Sativex-like combination of phytocannabinoids on disease progression in R6/2 mice, an experimental model of Huntington's disease. Int J Mol Sci 2017, 18, 684.

193. Fusar-Poli, P.; Crippa, J.A.; Bhattacharyya, S.; Borgwardt, S.J.; Allen, P.; Martin-Santos, R.; Seal, M.; Surguladze, S.A.; O'Carrol, C.; Atakan, Z. Distinct effects of $\Delta 9$-tetrahydrocannabinol and cannabidiol on neural activation during emotional processing. Archives of general psychiatry 2009, 66, 95-105.

194. Huang, H.-C.; Jiang, Z.-F. Accumulated amyloid- $\beta$ peptide and hyperphosphorylated tau protein: relationship and links in Alzheimer's disease. Journal of Alzheimer's disease 2009, 16, 15-27.

195. Braak, H.; Braak, E. Neuropathological stageing of Alzheimer-related changes. Acta neuropathologica 1991, $82,239-259$.

196. Hickman, S.E.; Allison, E.K.; El Khoury, J. Microglial dysfunction and defective $\beta$-amyloid clearance pathways in aging Alzheimer's disease mice. Journal of Neuroscience 2008, 28, 8354-8360.

197. Streit, W.J. Microglia and Alzheimer's disease pathogenesis. J Neurosci Res 2004, 77, 1-8.

198. Esposito, G.; Scuderi, C.; Savani, C.; Steardo, L., Jr.; De Filippis, D.; Cottone, P.; Iuvone, T.; Cuomo, V.; Steardo, L. Cannabidiol in vivo blunts beta-amyloid induced neuroinflammation by suppressing IL-1beta and iNOS expression. Br J Pharmacol 2007, 151, 1272-1279, doi:10.1038/sj.bjp.0707337.

199. Watt, G.; Karl, T. In vivo evidence for therapeutic properties of cannabidiol (CBD) for Alzheimer's disease. Front Pharmacol 2017, 8, 20.

200. Diomede, F.; Scionti, D.; Piattelli, A.; Grassi, G.; Pollastro, F.; Bramanti, P.; Mazzon, E.; Trubiani, O. Cannabidiol modulates the expression of Alzheimer's disease-related genes in mesenchymal stem cells. Int J Mol Sci 2017, 18, 26. 
201. Vallée, A.; Lecarpentier, Y.; Guillevin, R.; Vallée, J.-N. Effects of cannabidiol interactions with Wnt/ $\beta$ catenin pathway and PPAR $\gamma$ on oxidative stress and neuroinflammation in Alzheimer's disease. Acta Biochimica et Biophysica Sinica 2017, 49, 853-866, doi:10.1093/abbs/gmx073.

202. Ehrhart, J.; Obregon, D.; Mori, T.; Hou, H.; Sun, N.; Bai, Y.; Klein, T.; Fernandez, F.; Tan, J.; Shytle, R.D. Stimulation of cannabinoid receptor 2 (CB 2) suppresses microglial activation. Journal of neuroinflammation 2005, 2, 29.

203. Tolón, R.M.; Núñez, E.; Pazos, M.R.; Benito, C.; Castillo, A.I.; Martínez-Orgado, J.A.; Romero, J. The activation of cannabinoid CB2 receptors stimulates in situ and in vitro beta-amyloid removal by human macrophages. Brain research 2009, 1283, 148-154.

204. Harris, R.A.; Tindale, L.; Cumming, R.C. Age-dependent metabolic dysregulation in cancer and Alzheimer's disease. Biogerontology 2014, 15, 559-577.

205. Moon, H.E.; Paek, S.H. Mitochondrial dysfunction in Parkinson's disease. Experimental neurobiology 2015, 24, 103-116.

206. Thomas, B.; Beal, M.F. Mitochondrial therapies for Parkinson's disease. Movement disorders 2010, 25, S155S160.

207. Sveinbjornsdottir, S. The clinical symptoms of Parkinson's disease. Journal of neurochemistry 2016, 139, 318324.

208. Juknat, A.; Rimmerman, N.; Levy, R.; Vogel, Z.; Kozela, E. Cannabidiol affects the expression of genes involved in zinc homeostasis in BV-2 microglial cells. Neurochemistry international 2012, 61, 923-930, doi:10.1016/j.neuint.2011.12.002.

209. Garcia-Arencibia, M.; Gonzalez, S.; de Lago, E.; Ramos, J.A.; Mechoulam, R.; Fernandez-Ruiz, J. Evaluation of the neuroprotective effect of cannabinoids in a rat model of Parkinson's disease: importance of antioxidant and cannabinoid receptor-independent properties. Brain Res 2007, 1134, 162-170, doi:10.1016/j.brainres.2006.11.063.

210. Chagas, M.H.; Eckeli, A.L.; Zuardi, A.W.; Pena-Pereira, M.A.; Sobreira-Neto, M.A.; Sobreira, E.T.; Camilo, M.R.; Bergamaschi, M.M.; Schenck, C.H.; Hallak, J.E., et al. Cannabidiol can improve complex sleep-related behaviours associated with rapid eye movement sleep behaviour disorder in Parkinson's disease patients: a case series. Journal of clinical pharmacy and therapeutics 2014, 39, 564-566, doi:10.1111/jcpt.12179.

211. Chagas, M.H.; Zuardi, A.W.; Tumas, V.; Pena-Pereira, M.A.; Sobreira, E.T.; Bergamaschi, M.M.; dos Santos, A.C.; Teixeira, A.L.; Hallak, J.E.; Crippa, J.A. Effects of cannabidiol in the treatment of patients with Parkinson's disease: an exploratory double-blind trial. Journal of psychopharmacology (Oxford, England) 2014, 28, 1088-1098, doi:10.1177/0269881114550355.

212. Lastres-Becker, I.; Molina-Holgado, F.; Ramos, J.A.; Mechoulam, R.; Fernandez-Ruiz, J. Cannabinoids provide neuroprotection against 6-hydroxydopamine toxicity in vivo and in vitro: relevance to Parkinson's disease. Neurobiology of disease 2005, 19, 96-107, doi:10.1016/j.nbd.2004.11.009.

213. Garcia, C.; Palomo-Garo, C.; García-Arencibia, M.; Ramos, J.A.; Pertwee, R.G.; Fernández-Ruiz, J. Symptom-relieving and neuroprotective effects of the phytocannabinoid $\triangle 9$-THCV in animal models of Parkinson's disease. British journal of pharmacology 2011, 163, 1495-1506.

214. Lotan, I.; Treves, T.A.; Roditi, Y.; Djaldetti, R. Cannabis (medical marijuana) treatment for motor and nonmotor symptoms of Parkinson disease: An open-label observational study. Clinical neuropharmacology 2014, $37,41-44$.

215. Gugliandolo, A.; Pollastro, F.; Bramanti, P.; Mazzon, E. Cannabidiol exerts protective effects in an in vitro model of Parkinson's disease activating AKT/mTOR pathway. Fitoterapia 2020, 143, 104553, doi:10.1016/j.fitote.2020.104553.

216. Crippa, J.A.S.; Hallak, J.E.; Zuardi, A.W.; Guimarães, F.S.; Tumas, V.; dos Santos, R.G. Is cannabidiol the ideal drug to treat non-motor Parkinson's disease symptoms? European archives of psychiatry and clinical neuroscience 2019, 269, 121-133.

217. Peres, F.F.; Levin, R.; Suiama, M.A.; Diana, M.C.; Gouvea, D.A.; Almeida, V.; Santos, C.M.; Lungato, L.; Zuardi, A.W.; Hallak, J.E., et al. Cannabidiol Prevents Motor and Cognitive Impairments Induced by Reserpine in Rats. Front Pharmacol 2016, 7, 343, doi:10.3389/fphar.2016.00343.

218. Consroe, P.; Sandyk, R.; Snider, S.R. Open label evaluation of cannabidiol in dystonic movement disorders. International Journal of Neuroscience 1986, 30, 277-282.

219. Zuardi, A.W.; Crippa, J.; Hallak, J.E.C.; Pinto, J.; Chagas, M.H.N.; Rodrigues, G.; Dursun, S.; Tumas, V. Cannabidiol for the treatment of psychosis in Parkinson's disease. Journal of Psychopharmacology 2009, 23, 979-983. 
220. Englund, A.; Morrison, P.D.; Nottage, J.; Hague, D.; Kane, F.; Bonaccorso, S.; Stone, J.M.; Reichenberg, A.; Brenneisen, R.; Holt, D. Cannabidiol inhibits THC-elicited paranoid symptoms and hippocampaldependent memory impairment. Journal of psychopharmacology 2013, 27, 19-27.

221. Santos, N.A.G.; Martins, N.M.; Sisti, F.M.; Fernandes, L.S.; Ferreira, R.S.; Queiroz, R.H.C.; Santos, A.C. The neuroprotection of cannabidiol against MPP+-induced toxicity in PC12 cells involves trkA receptors, upregulation of axonal and synaptic proteins, neuritogenesis, and might be relevant to Parkinson's disease. Toxicology in Vitro 2015, 30, 231-240.

222. Trapp, B.D.; Nave, K.-A. Multiple sclerosis: an immune or neurodegenerative disorder? Annu. Rev. Neurosci. 2008, 31, 247-269.

223. Frohman, E.M.; Racke, M.K.; Raine, C.S. Multiple sclerosis - the plaque and its pathogenesis. New England Journal of Medicine 2006, 354, 942-955.

224. Compston, A.; Coles, A. Multiple sclerosis. Lancet (Lond, Engl) 372: 1502-1517. 2008.

225. Murray, E.; Buttner, E.; Price, B.J.D.R., Fenichel G, Jankovic J, Mazziotta J. Bradley's neurology in clinical practice.. Philadelphia, PA: Elsevier/Saunders. Depression and psychosis in neurological practice. Bradley's neurology in clinical practice.(6th ed.). Philadelphia, PA: Elsevier/Saunders. 2012 Apr 12. 2012.

226. Mammana, S.; Bramanti, P.; Mazzon, E.; Cavalli, E.; Basile, M.S.; Fagone, P.; Petralia, M.C.; McCubrey, J.A.; Nicoletti, F.; Mangano, K. Preclinical evaluation of the PI3K/Akt/mTOR pathway in animal models of multiple sclerosis. Oncotarget 2018, 9, 8263.

227. Coles, A.J.; Cox, A.; Le Page, E.; Jones, J.; Trip, S.A.; Deans, J.; Seaman, S.; Miller, D.H.; Hale, G.; Waldmann, H. The window of therapeutic opportunity in multiple sclerosis. Journal of neurology 2006, 253, 98-108.

228. Confavreux, C.; Vukusic, S. Natural history of multiple sclerosis: a unifying concept. Brain 2006, 129, 606616.

229. MARTIN, R.; METZ, I.; BRUCK, W.; LUCCHINETTI, C.F.; OPENSHAW, H. Autologous haematopoietic stem cell transplantation fails to stop demyelination and neurodegeneration in multiple sclerosis. Brain 2007, 130 .

230. Consroe, P.; Musty, R.; Rein, J.; Tillery, W.; Pertwee, R. The perceived effects of smoked cannabis on patients with multiple sclerosis. European neurology 1997, 38, 44-48.

231. Pertwee, R.G. Targeting the endocannabinoid system with cannabinoid receptor agonists: pharmacological strategies and therapeutic possibilities. Philosophical Transactions of the Royal Society B: Biological Sciences 2012, 367, 3353-3363.

232. Nielsen, S.; Germanos, R.; Weier, M.; Pollard, J.; Degenhardt, L.; Hall, W.; Buckley, N.; Farrell, M. The use of cannabis and cannabinoids in treating symptoms of multiple sclerosis: a systematic review of reviews. Current neurology and neuroscience reports 2018, 18, 8.

233. Elliott, D.M.; Singh, N.; Nagarkatti, M.; Nagarkatti, P.S. Cannabidiol attenuates experimental autoimmune encephalomyelitis model of multiple sclerosis through induction of myeloid-derived suppressor cells. Frontiers in immunology 2018, 9, 1782.

234. Perras, C. Sativex for the management of multiple sclerosis symptoms. Issues in emerging health technologies 2005, 1-4.

235. Meuth, S.G.; Henze, T.; Essner, U.; Trompke, C.; Vila Silvan, C. Tetrahydrocannabinol and cannabidiol oromucosal spray in resistant multiple sclerosis spasticity: consistency of response across subgroups from the SAVANT randomized clinical trial. The International journal of neuroscience 2020, 10.1080/00207454.2020.1730832, 1-7, doi:10.1080/00207454.2020.1730832.

236. Iskedjian, M.; Bereza, B.; Gordon, A.; Piwko, C.; Einarson, T.R. Meta-analysis of cannabis based treatments for neuropathic and multiple sclerosis-related pain. Current medical research and opinion 2007, 23, 17-24, doi:10.1185/030079906x158066.

237. Russo, E.B.; Guy, G.W.; Robson, P.J. Cannabis, pain, and sleep: lessons from therapeutic clinical trials of Sativex ${ }^{\circledR}$, a cannabis-based medicine. Chemistry $\mathcal{E}$ biodiversity 2007, 4, 1729-1743.

238. Croxford, J.L.; Pryce, G.; Jackson, S.J.; Ledent, C.; Giovannoni, G.; Pertwee, R.G.; Yamamura, T.; Baker, D. Cannabinoid-mediated neuroprotection, not immunosuppression, may be more relevant to multiple sclerosis. Journal of neuroimmunology 2008, 193, 120-129.

239. Wein, A.J. An Open-Label Pilot Study of Cannabis-Based Extracts for Bladder Dysfunction in Advanced Multiple Sclerosis. The Journal of urology 2005, 10, 425-433.

240. Cotran, R.S.; Kumar, V.; Collins, T.; Robbins, S.L. Giant cell tumor of tendon sheath and pigmented villonodular synovitis. Robbins pathologic basis of disease. 6th ed. Philadelphia: WB Saunders 1999, 1258-1259. 
241. Dirikoc, S.; Priola, S.A.; Marella, M.; Zsurger, N.; Chabry, J. Nonpsychoactive cannabidiol prevents prion accumulation and protects neurons against prion toxicity. J Neurosci 2007, 27, 9537-9544, doi:10.1523/jneurosci.1942-07.2007.

242. Verkhratsky, A.; Toescu, E. Endoplasmic reticulum Ca2+ homeostasis and neuronal death. Journal of cellular and molecular medicine 2003, 7, 351-361.

243. Silei, V.; Fabrizi, C.; Venturini, G.; Salmona, M.; Bugiani, O.; Tagliavini, F.; Lauro, G.M. Activation of microglial cells by $\operatorname{PrP}$ and $\beta$-amyloid fragments raises intracellular calcium through L-type voltage sensitive calcium channels. Brain research 1999, 818, 168-170.

244. Florio, T.; Grimaldi, M.; Scorziello, A.; Salmona, M.; Bugiani, O.; Tagliavini, F.; Forloni, G.; Schettini, G. Intracellular calcium rise through L-type calcium channels, as molecular mechanism for prion protein fragment 106-126-induced astroglial proliferation. Biochemical and biophysical research communications 1996, 228, 397-405.

245. Marella, M.; Chabry, J. Neurons and astrocytes respond to prion infection by inducing microglia recruitment. Journal of Neuroscience 2004, 24, 620-627.

246. Hardiman, O.; Van Den Berg, L.H.; Kiernan, M.C. Clinical diagnosis and management of amyotrophic lateral sclerosis. Nature reviews neurology 2011, 7, 639.

247. Miller, R.; Jackson, C.E.; Kasarskis, E.; England, J.; Forshew, D.; Johnston, W.; Kalra, S.; Katz, J.; Mitsumoto, H.; Rosenfeld, J. Practice parameter update: the care of the patient with amyotrophic lateral sclerosis: multidisciplinary care, symptom management, and cognitive/behavioral impairment (an evidence-based review): report of the Quality Standards Subcommittee of the American Academy of Neurology. Neurology 2009, 73, 1227-1233.

248. Zarei, S.; Carr, K.; Reiley, L.; Diaz, K.; Guerra, O.; Altamirano, P.F.; Pagani, W.; Lodin, D.; Orozco, G.; Chinea, A. A comprehensive review of amyotrophic lateral sclerosis. Surg Neurol Int 2015, 6, 171-171, doi:10.4103/2152-7806.169561.

249. Raman, C.; McAllister, S.D.; Rizvi, G.; Patel, S.G.; Moore, D.H.; Abood, M.E. Amyotrophic lateral sclerosis: delayed disease progression in mice by treatment with a cannabinoid. Amyotrophic lateral sclerosis and other motor neuron disorders : official publication of the World Federation of Neurology, Research Group on Motor Neuron Diseases 2004, 5, 33-39, doi:10.1080/14660820310016813.

250. Rajan, T.S.; Scionti, D.; Diomede, F.; Grassi, G.; Pollastro, F.; Piattelli, A.; Cocco, L.; Bramanti, P.; Mazzon, E.; Trubiani, O. Gingival Stromal Cells as an In Vitro Model: Cannabidiol Modulates Genes Linked With Amyotrophic Lateral Sclerosis. Journal of cellular biochemistry 2017, 118, 819-828, doi:10.1002/jcb.25757.

251. Riva, N.; Mora, G.; Soraru, G.; Lunetta, C.; Ferraro, O.E.; Falzone, Y.; Leocani, L.; Fazio, R.; Comola, M.; Comi, G. Safety and efficacy of nabiximols on spasticity symptoms in patients with motor neuron disease (CANALS): a multicentre, double-blind, randomised, placebo-controlled, phase 2 trial. The Lancet. Neurology 2019, 18, 155-164, doi:10.1016/s1474-4422(18)30406-x.

252. Meyer, T.; Funke, A.; Münch, C.; Kettemann, D.; Maier, A.; Walter, B.; Thomas, A.; Spittel, S. Real world experience of patients with amyotrophic lateral sclerosis (ALS) in the treatment of spasticity using tetrahydrocannabinol: cannabidiol (THC: CBD). BMC neurology 2019, 19, 222.

253. Urbi, B.; Broadley, S.; Bedlack, R.; Russo, E.; Sabet, A. Study protocol for a randomised, double-blind, placebo-controlled study evaluating the Efficacy of cannabis-based Medicine Extract in slowing the disease pRogression of Amyotrophic Lateral sclerosis or motor neurone Disease: the EMERALD trial. BMJ Open 2019, 9, e029449-e029449, doi:10.1136/bmjopen-2019-029449.

254. Moreno, J.L.L.-S.; Caldentey, J.G.; Cubillo, P.T.; Romero, C.R.; Ribas, G.G.; Arias, M.A.A.; De Yébenes, M.J.G.; Tolón, R.M.; Galve-Roperh, I.; Sagredo, O. A double-blind, randomized, cross-over, placebocontrolled, pilot trial with Sativex in Huntington's disease. Journal of neurology 2016, 263, 1390-1400.

255. Scuderi, C.; Steardo, L.; Esposito, G. Cannabidiol promotes amyloid precursor protein ubiquitination and reduction of beta amyloid expression in SHSY5YAPP+ cells through PPAR $\gamma$ involvement. Phytotherapy research 2014, 28, 1007-1013.

256. Martín-Moreno, A.M.; Reigada, D.; Ramírez, B.G.; Mechoulam, R.; Innamorato, N.; Cuadrado, A.; de Ceballos, M.L. Cannabidiol and other cannabinoids reduce microglial activation in vitro and in vivo: relevance to Alzheimer's disease. Molecular pharmacology 2011, 79, 964-973.

257. Aso, E.; Sánchez-Pla, A.; Vegas-Lozano, E.; Maldonado, R.; Ferrer, I. Cannabis-based medicine reduces multiple pathological processes in A PPP/PS1 mice. Journal of Alzheimer's Disease 2015, 43, 977-991.

258. Asó, E.; Andrés-Benito, P.; Ferrer, I. Delineating the efficacy of a cannabis-based medicine at advanced stages of dementia in a murine model. Journal of Alzheimer's Disease 2016, 54, 903-912. 
259. Casarejos, M.J.; Perucho, J.; Gomez, A.; Munoz, M.P.; Fernandez-Estevez, M.; Sagredo, O.; Fernandez Ruiz, J.; Guzman, M.; de Yebenes, J.G.; Mena, M.A. Natural cannabinoids improve dopamine neurotransmission and tau and amyloid pathology in a mouse model of tauopathy. Journal of Alzheimer's Disease 2013, 35, 525539.

260. Sonego, A.B.; Gomes, F.V.; Del Bel, E.A.; Guimaraes, F.S. Cannabidiol attenuates haloperidol-induced catalepsy and c-Fos protein expression in the dorsolateral striatum via 5-HT1A receptors in mice. Behavioural brain research 2016, 309, 22-28.

261. Zhou, T.; Ahmad, T.K.; Alrushaid, S.; Pozdirca, M.; Ethans, K.; Intrater, H.; Le, T.; Burczynski, F.; Kong, J.; Namaka, M. Therapeutic impact of orally administered cannabinoid oil extracts in an experimental autoimmune encephalomyelitis animal model of multiple sclerosis. Biochem Biophys Res Commun 2019, 516, 373-380, doi:10.1016/j.bbrc.2019.06.033.

262. Brady, C.; DasGupta, R.; Dalton, C.; Wiseman, O.; Berkley, K.; Fowler, C.J.M.S.J. An open-label pilot study of cannabis-based extracts for bladder dysfunction in advanced multiple sclerosis. Multiple Sclerosis Journal 2004, 10, 425-433.

263. Scott, K.A.; Dennis, J.L.; Dalgleish, A.G.; Liu, W.M. Inhibiting heat shock proteins can potentiate the cytotoxic effect of cannabidiol in human glioma cells. Anticancer research 2015, 35, 5827-5837.

264. Gupta, A.; Bansal, A.; Hashimoto-Torii, K. HSP70 and HSP90 in neurodegenerative diseases. Neuroscience Letters 2020, 716, 134678, doi:https://doi.org/10.1016/j.neulet.2019.134678.

265. Christ, M.G.; Clement, A.M.; Behl, C. The Sigma-1 Receptor at the Crossroad of Proteostasis, Neurodegeneration, and Autophagy. Trends in Neurosciences 2020, 43, 79-81, doi:https://doi.org/10.1016/j.tins.2019.12.002.

266. Schrock, J.M.; Spino, C.M.; Longen, C.G.; Stabler, S.M.; Marino, J.C.; Pasternak, G.W.; Kim, F.J. Sequential cytoprotective responses to Sigma1 ligand-induced endoplasmic reticulum stress. Molecular pharmacology 2013, 84, 751-762, doi:10.1124/mol.113.087809.

267. Sánchez-Blázquez, P.; Rodríguez-Muñoz, M.; Herrero-Labrador, R.; Burgueño, J.; Zamanillo, D.; Garzón, J. The calcium-sensitive Sigma-1 receptor prevents cannabinoids from provoking glutamate NMDA receptor hypofunction: implications in antinociception and psychotic diseases. The international journal of neuropsychopharmacology 2014, 17, 1943-1955, doi:10.1017/s1461145714000029.

268. Zenke-Kawasaki, Y.; Dohi, Y.; Katoh, Y.; Ikura, T.; Ikura, M.; Asahara, T.; Tokunaga, F.; Iwai, K.; Igarashi, $\mathrm{K}$. Heme induces ubiquitination and degradation of the transcription factor Bach1. Molecular and cellular biology 2007, 27, 6962-6971, doi:10.1128/mcb.02415-06.

269. Ligresti, A.; Moriello, A.S.; Starowicz, K.; Matias, I.; Pisanti, S.; De Petrocellis, L.; Laezza, C.; Portella, G.; Bifulco, M.; Di Marzo, V. Antitumor activity of plant cannabinoids with emphasis on the effect of cannabidiol on human breast carcinoma. The Journal of pharmacology and experimental therapeutics 2006, 318, 1375-1387, doi:10.1124/jpet.106.105247.

270. Samara, E.; Brown, N.; Harvey, D. Microsomal metabolism of th e1, 1-dimethlheptyl analogue of cannabidiol: relative percentage of monhohydroxy in four species. Drug metabolism and disposition 1990, 18, 548-549. 